\title{
Group Identity, Performance Transparency, and Employee Performance
}

\author{
Ruidi Shang \\ Tilburg University, Netherlands \\ r.shang@uvt.nl \\ Margaret A Abernethy \\ University of Melbourne, Australia \\ m.abernethy@unimelb.edu.au \\ Chung-Yu Hung \\ University of Melbourne, Australia \\ chung-yu.hung@unimelb.edu.au
}

We thank Michael Williamson (the Editor) and the two anonymous reviewers for their helpful comments. We also thank Shannon Anderson, Eddy Cardinaels, Dennis Campbell, Tatiana Sandino, Sally Widener, and seminar participants at Harvard Business School, Tilburg University, University of Melbourne, the 2017 Global Management Accounting Research Symposium (GMARS), and the 2018 Management Accounting Section (MAS) Midyear Meeting for their constructive feedback. We acknowledge the financial support of the Accounting Department in the University of Melbourne. We thank the company in this study for providing us with data. 


\title{
Group Identity, Performance Transparency, and Employee Performance
}

\begin{abstract}
Economics, social psychology, and management studies suggest that group identity plays an important role in directing employee behaviors. On the one hand, strong group identity could motivate high effort by resolving conflicts of interests in the workplace. On the other hand, it could encourage conformity towards group norms. We examine whether the effect of group identity is conditional on managers' performance reporting choices. Drawing on survey and archival data from a field site, we find that when performance transparency is low, the interest alignment effect is more salient and group identity positively relates to employee performance. However, when performance transparency is high, the conformity effect is more salient and higher group identity is associated with more homogeneous, but not necessarily higher, employee performance. Our findings contribute to the management control literature by documenting that managers' performance reporting choices determine whether group identity has positive effects on employee performance.
\end{abstract}

Keywords: Employee Performance, Group Identity, Performance Transparency, Management Control, Management Accounting

Data availability: Data in this study are derived from a proprietary source. 


\section{INTRODUCTION}

Economists suggest that agency issues within firms can be alleviated by increasing employees' identification with their workgroup. In particular, identity economics predicts that employees' group identity can motivate higher effort and performance through an "interest alignment" effect (Akerlof and Kranton 2005). However, this is not always the case, as evidence indicates that group identity may also result in employees conforming to the performance of others (Benjamin, Choi, and Strickland 2010; Terry, Hogg, and White 1999). This "conformity" effect will lead to more homogeneous, but not necessarily higher employee performance. Given the different performance implications of the two effects, it is important to understand whether managers can influence the effect of group identity through their control choices.

We examine whether the relation between group identity and employee performance depends on managers' choice of performance reporting transparency. Psychology studies indicate that information about others' behaviors is the key to activating individuals' conformity (Cialdini and Trost 1998; Cialdini and Goldstein 2004). We argue that when employees have information about each other's performance (i.e., performance transparency is high), those with high group identity are motivated to adjust their actions to look more similar to other members in their group. That is, some employees may work harder, while others may "withhold" their effort to conform to the performance of others in their group. However, the conformity effect is less likely to occur if employees do not receive information about others' performance (i.e., performance transparency is low). In this case, the interest alignment effect is likely to be more salient. Without having others' performance as a "reference", employees with high group identity may be motivated to work hard and demonstrate high performance to reinforce their image as group members. Overall, we predict 
that the conformity (interest alignment) effect of group identity is more salient when performance transparency is high (low).

We test our hypotheses by exploiting a field-based dataset which has within-group variation in employees' group identity and between-group variation in performance transparency. Our research site includes three workgroups within the same department of a Chinese state-owned enterprise (SOE). These groups have the same structure, tasks, operating environments, as well as evaluation and reward systems. Two of these groups have high performance transparency where employees receive information about each other's performance; and one has low performance transparency where employees only receive information about their own performance. Employees cannot influence the group assignment or the reporting choice of their group, and the working environments are similar across the three groups. This variation provides us with an opportunity to examine the role of performance transparency.

A key feature of this setting is that the group structure and the operating environment have been stable for a long period of time which allows group identity and work norms to develop. This feature enables us to provide evidence on the effect of group identity, especially its potential effect in motivating employees' conformity toward the group norm. Additionally, other controls such as financial incentives and promotions are relatively weak in this setting due to the nature of the tasks and Chinese SOEs' practices. The role of group identity is particularly important and salient in a setting like this, and its effect is unlikely to be ruled out by formal incentives (Akerlof and Kranton 2005).

Our data comes from two sources: (a) archival data on employee performance and demographic characteristics, and (b) employees' response to a survey administered on site. Our measure of employees' group identity is based on an instrument validated in prior studies 
(Abernethy, Bouwens, and Kroos 2017; Boivie, Lange, McDonald, and Westphal 2011). Although this measure is captured at one point in time, group identity is a stable cognitive state which is unlikely to change unless there are significant changes in group structure (Bergami and Bagozzi 2000; Mael and Ashforth 1992). We use the level of individual performance as the dependent variable to assess the interest alignment effect of group identity, and the performance "gap" (i.e. the difference between individual performance and the group norm) to test the conformity effect.

Our findings suggest that the relation between employees' group identity and performance depends on the performance transparency within a group. First, we find that employees' group identity is positively (negatively) associated with their performance level when performance transparency is low (high). This evidence is consistent with the prediction that the interest alignment effect of group identity is more salient when performance information is less transparent. Second, we find that group identity is associated with a smaller performance gap when performance transparency is high than when it is low. This is consistent with the prediction that the conformity effect of group identity is more salient when performance information is more transparent in the workplace.

While the interest alignment effect is associated with higher performance, the performance outcomes of the conformity effect are unclear. Some employees may increase their performance (i.e., upward conformity) and others may decrease their performance (i.e., downward conformity) to conform to the other group members. To shed light on this question, we examine whether employees' ability relates to the direction of their conformity. We find that when performance transparency is high, group identity is associated with a downward conformity for high ability employees and an upward conformity for low ability employees. That is, for high- (low-) ability employees, group identity is negatively (positively) associated with the level of their performance. 
We do not find a similar pattern in the groups with low performance transparency. In other words, the conformity effect of group identity is only salient when performance transparency is high.

Taken together, our findings demonstrate that the relationship between group identity and employee performance is conditional on performance transparency. Our study contributes to the management control literature in three ways. First, our study extends the emerging literature on employees' group identity and behaviors (Chen and Li 2009; Goette, Huffman, and Meier 2006; Towry 2003). Identity economics and recent accounting studies demonstrate the interest alignment effect of employees' identity (Akerlof and Kranton 2005; Abernethy et al. 2017). Our study extends this literature by documenting that employees' identity can have a negative effect on their performance due to the conformity effect.

Second, our findings add to the performance transparency literature. While some studies document the benefits of performance transparency in terms of motivating effort (Hannan, McPhee, Newman, and Tafkov 2013; Tafkov 2013) and mitigating misreporting (Maas and Van Rinsum 2013), others suggest that performance transparency could lead to undesired employee behaviors such as effort misallocation (Hannan, Krishnan, and Newman 2008) and collusion (Maas and Yin 2018). We contribute to this literature by providing evidence about the joint effect of performance transparency and group identity. That is, performance transparency can have adverse consequence in the presence of strong employee group identity.

Third, in documenting the importance of the match between group identity and performance transparency, our study also adds to the economics literature on how the complementarity in control choices influences employee performance and productivity (Blader, Gartenberg, and Prat 2016; Ichniowski, Shaw, and Prennushi 1997; Milgrom and Roberts 1990, 1995). For example, our study is related to Bandiera, Barankay and Rasaul (2005, 2010), who provide evidence 
suggesting that social networks in the workplace can lead to conformity by activating employees' social incentives and social preferences. We add to these studies by documenting that employees' group identity can also lead to conformity. Further, we highlight that performance transparency, an important management control choice, can be used to activate or mute the conformity effect of group identity. In this regard, our study has practical implications. Our findings suggest that managers need to consider employees' group identity and ability when designing the performance report. For example, if workgroups have developed a high group identity and the majority of employees have high ability, creating performance transparency can lift the performance of low performers. However, if creating such an information environment results in conformity to a lower than desired level of effort, then it would be preferable for managers to privately communicate performance information to employees.

The remainder of this paper is organized as follows. The next section defines the theoretical constructs and develops the hypotheses. This is followed by a description of the research site and the method, results, and concluding comments.

\section{LITERATURE AND HYPOTHESIS}

\section{Group Identity in Organizations}

An important feature of organizations is that employees are typically structured into groups (Akerlof and Kranton 2005). "Group identity" occurs when individuals derive a sense of self from being a part of their group. It results from a cognitive process, through which individuals stop thinking like a unique person and instead think like representatives of their group (Tajfel and Turner 1986). Individuals with strong group identity are motivated to engage in identity-related behaviors to reinforce their image as group members and enhance their self-esteem (Akerlof and 
Kranton 2000, 2010). ${ }^{1}$ Prior research documents the benefits of group identity, including improved coordination, cooperation, and mutual monitoring between group members. Specifically, individuals with high group identity are more cooperative and altruistic when interacting with other members in their group (Chen and Li 2009 Goette et al. 2006). In the accounting literature, Towry (2003) finds that group identity increases the coordination between employees by encouraging them to monitor and control each other's actions.

While prior studies focus on how group identity influence employees' interactions with each other, we know little about whether employees' group identity affects their effort level when performing tasks individually. There are two ways in which group identity could affect employee performance. On the one hand, it can help to resolve conflicts of interest in the workplace and motivate employees to direct their effort to desired outcomes. Identity economics suggests that employees with strong group identity think of themselves as "insiders" of their group and derive utility from acting in the best interests of the principal. The implication is that employees with strong group identity tend to demonstrate high performance and avoid opportunistic behaviors, even when financial incentives are weak or absent (Akerlof and Kranton 2000, 2005, 2010). We refer to this effect as the "interest alignment" effect of group identity.

On the other hand, when employees see themselves as part of a group, they tend to adopt the behaviors that are consistent with what most other group members do, i.e., the group norm (Chen and Li 2009). Conforming to the group norm increases one's similarity with other group members

\footnotetext{
${ }^{1}$ Group identity is a cognitive construct, and more specifically, a self-perception. It differs from any specific behaviors (e.g., effort), affective states (e.g., loyalty and commitment), and attitudes (e.g., acceptance of group norms and internalization of group values and/or goals). However, empirically, group identity could be associated with these factors (Ashforth and Mael 1989; Bergami and Bagozzi 2000). Identity economics suggests that what differentiates individuals with strong group identity from those with weak group identity is the extent to which they care about their self-image as group members more than their own financial payoffs (Akerlof and Kranton 2000, 2003, 2005, 2010). That is, group identity is associated with the psychological utility and can be shaped or influenced by different factors in the workplace.
} 
and reinforce his/her image as a part of the group (Akerlof and Kranton 2010; Terry, Hogg, and White 1999). Existing literature makes no assumption about whether conforming to the group norm leads to desirable outcomes, but simply predicts that employees who have strong group identity are less likely to deviate from the group norm than those with weak group identity, namely, that there is a "difference aversion". We refer to this phenomenon as the "conformity" effect of group identity.

Distinguishing the interest alignment and conformity effects is important, as they may lead to different performance outcomes. The interest alignment effect is generally assumed to have a positive influence on performance, while the outcome of the conformity effect is ambiguous since group identity could lead to either upward or downward conformity in performance. However, there is little evidence about which effect is more salient and under what conditions. We address this question by examining the performance implications of group identity in different information environments. Whether the conformity effect is activated depends on the information received by employees. If employees do not have information about the group norm, they cannot conform. However, if they have information about other group members' performance, the conformity effect may become salient.

\section{Performance Transparency}

Whether employees receive information about others' performance is determined by the performance transparency in their group. Performance transparency is an important control choice that determines how employees are affected by others around them (Cardinaels and Yin 2015; Eyring and Narayanan 2018; Hannan et al. 2013; Maas and Van Rinsum 2013; Sliwka 2007; Tafkov 2013; Tayler and Bloomfield 2011). Social comparison theory (Festinger 1954) posits that individuals have a drive to continually compare themselves to others in order to evaluate their 
positions in a social context. Performance transparency enables employees to observe the performance of others around them and use this information as a "reference" to evaluate themselves.

We investigate how performance transparency relates to the effects of group identity (i.e., the interest alignment effect and the conformity effect). We predict that the conformity effect of group identity will be activated when performance transparency is high (i.e., employees receive information about the performance of other group members). We draw on the insights provided by Sliwka's (2007) theoretical model to illustrate how performance transparency activates the conformity effect of group identity. His model recognizes that certain employees have preferences to conform, i.e., the conformists. Conformists can behave either cooperatively or opportunistically depending on their view of other employees. Sliwka (2007) argues that a principal's contract choice (e.g., incentive vs. fixed wage contract) reveals information about the majority of employees' behaviors, and in turn, affects conformists' behavior. When conformists observe fixed wage (incentive) contracts being offered, they think that other employees are cooperative (opportunistic) and they will behave cooperatively (opportunistically) accordingly. Using an experimental setting, Cardinaels and Yin (2015) provide empirical evidence that is consistent with Sliwka's (2007) prediction about the choice of compensation contracts and employees' conformity.

The important insight from Sliwka (2007) and Cardinaels and Yin (2015) is that employees’ information regarding others' behavior will determine conformists' views and behaviors. This relates to our setting in which employees with strong group identity are inclined to conform to the behaviors of other group members. If information about other employees' performance is available (i.e., performance transparency is high), it could activate the conformity effect of group identity because those with strong group identity will know the group norm and have the motivation to 
follow. However, the conformity effect is less likely to occur when employees know little about others' behaviors (i.e. performance transparency is low). Therefore, we predict that performance transparency will magnify the conformity effect of group identity.

In sum, the association between employees' group identity and their performance is subject to interest alignment and conformity effects. Drawing on the literature studying the relation between performance transparency and conformity, we expect that managers' choice regarding performance transparency determines which effect is more salient. We predict that the interest alignment effect is more salient under low performance transparency, whereas the conformity effect is more pronounced under high performance transparency. ${ }^{2}$ We use performance "level" and "gap" to examine these effects of group identity. We use the level of employee performance to examine the interest alignment effect, as it predicts that stronger group identity is associated with higher performance. In comparison, the conformity effect suggests that stronger group identity is associated with more homogeneous employee performance. We thus use the "gap" between an employee's performance and the group norm to examine the conformity effect.

We develop hypotheses about how group identity is associated with employee performance in groups with different levels of performance transparency. In groups with low performance transparency, employees with strong group identity are motivated to exert high effort (i.e., the interest alignment effect is more salient), whereas in groups with high performance transparency, employees with strong group identity may increase or "withhold" their effort to conform to others in the same group (i.e., the conformity effect is more salient). Although both effects could motivate the low-performers to improve their performance, the conformity (interest alignment) effect would lead to lower (higher) performance of the high-performers. Therefore, we expect that group

\footnotetext{
${ }^{2}$ Give that high and low performance transparency cannot coexist in the same group, we have no prediction about the average/main relationship between group identity and employee performance.
} 
identity is associated with lower (higher) performance level and smaller (greater) performance gap under higher performance transparency than under low performance transparency. Our expectations are summarized as follows:

$H_{1}$ : Group identity is associated with higher performance levels in groups with low performance transparency than in groups with high performance transparency.

$\mathrm{H}_{2}$ : Group identity is associated with smaller performance gaps in groups with high performance transparency than in groups with low performance transparency.

It is difficult to develop a directional prediction about how group identity is associated with employees' performance level when the conformity effect is salient, as some employees may increase their effort, while others may decrease their effort to conform to others in their workgroup. Our intuition is that the direction of individuals' conformity will depend on their ability. Ability is an important determinant of task performance (Smith and Arnkelsson 2000). If group identity activates employees' desire to conform to other group members, those with high ability may withhold their effort and achieve a performance level which is lower than what they would otherwise achieve (i.e., downward conformity). Similarly, those with low ability will try to conform to other group members by exerting greater effort to achieve a higher performance level (i.e., upward conformity). Overall, when the conformity effect is activated by high performance transparency, the relation between employees' group identity and their performance outcomes will depend on their ability. We expect a negative (positive) relation between employees' group identity and performance level for high-ability (low-ability) employees. We test if this is the case in our empirical analysis. 


\section{RESEARCH SITE}

We examine our hypotheses using archival and survey data from three workgroups in a Chinese state-owned enterprise (SOE). ${ }^{3}$ These groups are in the same department where employees work on equipment inspection, operation, and maintenance. There are three shifts every day to ensure that the equipment functions 24/7. During each shift, employees work individually in different sections of the workshop where they cannot observe or interact with each other. The upper level management of the organization divides employees into three workgroups to make these shifts easy to manage, and there is no evidence indicating that the allocation is not random. ${ }^{4}$ Overall, the three workgroups are comparable as they have the same structure, tasks, and performance measurement and reward systems.

We choose this research site to conduct our study for several reasons. First, group identity plays an important role in directing employee behaviors in settings where other controls (such as financial incentives and promotions) are weak (Akerlof and Kranton 2000, 2005). This is the case in our setting. Historically, the SOE in our study has not relied on steep financial incentives due to the cultural norms of Chinese SOEs and government regulations. Further, most employees in the SOE are responsible for guardian tasks which require them to avoid any risky actions. ${ }^{5}$ Using steep

\footnotetext{
${ }^{3}$ This SOE was established in the early 1980s and now comprises multiple subunits such as factories and plants. We obtained archival and survey data from a power plant in the SOE which has seven operational departments, each managed by a department manager. Within each department, there are five to 10 workgroups. Only one of those departments (i.e., the one used in our study) consists of workgroups that have comparable tasks and group structure, and a variation in performance transparency. The SOE has a hierarchical structure with centralized decision making; department managers and group leaders have limited decision rights. Specifically, the upper level management of the SOE makes decisions about the task design, the structure of departments and workgroups, and the management control mechanisms. The department managers have limited discretion when executing these decisions.

${ }^{4}$ Appendix 2 presents employees' characteristics of each group. We do not find significant differences in most of employees' characteristics (e.g., age, tenure, education, and hometown), except in their political affiliation (i.e., whether they are communist party members). Due to the relatively small proportion of communist party members in this setting, a small difference between different groups can be statistically significant. Note that we control all of these observed characteristics in our regression analyses.

${ }^{5}$ Baron and Kreps (1999) divided employee tasks into three types based on the link between employee performance and firm performance: star, foot-soldier, and guardian tasks. A guardian job is one in which good performance adds little value, but bad performance is a disaster (e.g., auditing or equipment maintenance tasks).
} 
financial incentives could increase the risks of mechanical failure and/or operational disasters by encouraging employees to concentrate on the actions that can be precisely measured and ignore the actions that cannot easily be measured. Additionally, our analysis of the employee data also indicates that other types of incentives (e.g. promotion opportunities) are not in place. ${ }^{6}$ The virtual absence of formal incentives in this setting provides an environment where group identity can be salient and play a particularly important role in directing employee performance.

Second, our observations in the field and our initial data analysis suggest that employees identify with their workgroup to varying degrees. We observed several features of this setting: (a) there is low employee turnover rate, as the SOE cannot easily fire its employees due to government regulations $;^{7}$ (b) the compensation and other benefits of this SOE are better than that of other organizations in the local area so most employees choose to stay in the SOE until retirement; (c) the group structure is stable across time and the change of group or position rarely happens, meaning that once allocated into a workgroup, employees usually stay in the same group for years; and (d) employees in a group work the same shift and engage in a number of activities together (e.g., have lunch, take buses, and attend group/department meetings, etc.). Given these features, there are opportunities for group identity to develop. Further, our initial data analysis suggests variation in the extent to which employees identify with their group. These features enable us to examine the relation between employees' group identity and their performance. We explore which factors explain the variation in employees' group identity in our additional analyses.

\footnotetext{
${ }^{6}$ The operating environment is stable in the SOE. Department managers and group leaders are directly appointed by upper level management, based on seniority, political affiliation, and leadership (subjectively assessed by the upper level management team).

${ }^{7}$ For each of our sample groups, there were two to three employees who retired during our sample period. Besides those retirements, there was no other voluntary or involuntary turnover during our sample period.
} 
Finally, there is a variation in performance transparency between different groups. In each group, there is one employee who acts as the group leader and is responsible for distributing the performance information to other employees. Two types of performance reporting practices have coexisted in our setting for years. In particular, group leaders print out the names and performance information of each group member as a table. Some group leaders choose to cut the performance table into pieces, and provide each group member with the piece of information regarding his or her performance only. In other words, performance transparency is low in these groups, as performance information is privately communicated to each employee. In comparison, the other group leaders choose to post or pass around the performance table within their workgroups, without cutting it into individual performance reports. Performance transparency is high in these groups, given that performance information is publicly communicated among employees. Appendix 1 visually compares the two reporting choices in the research site. In both types of groups, the performance information is structured in the same way, as required by the upper level management. The only difference is the way in which group leaders distribute the performance information. ${ }^{8}$ We can treat this variation as exogenous in our empirical model, given that employees cannot influence the group assignment, the appointment of group leaders, or the reporting practices of group leaders. This variation enables us to examine whether performance transparency determines how employees' group identity relates to their performance. ${ }^{9}$

\footnotetext{
8 The purpose of reporting performance information is to follow the requirement set by upper level management that each employee must receive information about his/her own performance. After discussing with the department managers and group leaders, we find no evidence that group leaders planned to use performance reporting to influence employee performance, neither do they have the decision rights to implement control mechanisms that are not used in other groups. Further, we find that group leaders' reporting practices are not explained by any of their characteristics that we can observe. The leaders of the three groups in our setting have very similar characteristics (i.e., male, local, born in the middle 1970s, have a senior high school or vocational school degree, and have joined the Chinese communist party).

${ }^{9}$ It is possible for employees in the same group to discuss their performance with each other in private. Compared with this informal information sharing among employees, the information disclosed by the group leader comprehensively covers the performance of all employees within a group and is available to all group members.
} 


\section{RESEARCH METHOD}

\section{Data}

We obtain both archival and survey data from the research site to test our hypotheses. ${ }^{10} \mathrm{We}$ collect archival data on employees' monthly performance and their demographic characteristics (e.g., gender, education, hometown, etc.) over January 2011 to July 2015 from the central office of the research site. In line with prior research, we use a survey questionnaire to measure employees' group identity (Abernethy et al. 2017; Boivie et al. 2011; Mael and Ashforth 1992). As individuals' group identity is a cognitive construct, it is appropriate to measure it using survey questions at the individual level (Bergami and Bagozzi 2000). Based on prior research, we used the English version of the survey (e.g., Abernethy et al. 2017; Boivie et al. 2011; Mael and Ashforth 1992) and translated the questions into Chinese. ${ }^{11}$

The survey sample is not limited to our research sample which covers the three selected groups of employees within the same department. We administered the survey to 445 employees in four departments of our research site in May 2015 using the internal mailing system of the SOE and 254 employees responded (response rate $=57 \%$ ). ${ }^{12}$ Within our research sample, there was a reasonable response rate to the survey with 51 of the 94 employees responding (response rate $=$ $54 \%)$. We checked the representativeness of the responses, that is, whether the employees in our sample (i.e., the survey respondents) are representative of all employees (i.e., the respondents and the non-respondents) in our sample groups (Van der Stede, Young, and Chen 2005). In terms of

That is, the level of performance transparency is higher in the groups that publicly disclose everyone's performance than in the groups without such disclosure.

${ }^{10} \mathrm{We}$ obtained ethical approval for collecting and using the field data.

${ }^{11}$ We sought advice from a professional translator to check our translation from English to Chinese.

${ }^{12}$ We administered the survey during the period in which the SOE gave us access to visit our research site and distribute the survey questionnaires. We followed the standard survey procedure by mailing the paper-based questionnaires to employees' work addresses. Attached with the questionnaire is a consent form. By signing the consent, employees agree that they understand that the purpose of this survey is for research, their participation is voluntary, they are free to withdraw any time, and their confidentiality will be protected subject to legal requirements. 
age, tenure, gender, hometown, education, and political affiliations, Panel A of Appendix 3 indicates that there is no significant difference between the respondents and the non-respondents. Thus, we believe that non-response bias is not likely to affect our results significantly.

In the survey, we also collect data to test the construct validity of the group identity measure, and we collect additional information to construct several control variables (e.g., employees' social connections in the SOE, and their view on the control mechanisms adopted in the SOE). It is worthwhile to highlight that we validate our survey instrument using the full survey sample, and then retrieve the responses corresponding to our research sample for the empirical analyses. Although our survey-based measure of employees' group identity is a snapshot measure, group identity is a stable cognitive state which is unlikely to change unless there are dramatic changes in the group and/or the individual (Bergami and Bagozzi 2000; Mael and Ashforth 1992). The stable nature of identity is further supported by the research site as it has a stable working environment. During our sample period, no employees switched groups, and there was no dramatic change or group restructure which may affect the variation of employees' group identity. For these reasons, our measure using the survey instrument is, at least over our sample period, a reasonable reflection of employees' group identity.

\section{Variables}

\section{Group Identity (GI)}

Our variable of interest, employees' group identity, is measured using seven survey questions that were developed and validated by previous studies (Abernethy et al. 2017; Bartel 2001; Bergami and Bagozzi 2000; Boivie et al. 2011; Dukerich, Golden, and Shortell 2002; Johnson, Morgeson, Ilgen, and Meyer 2006; Mael and Ashforth 1992; Shamir and Kark 2004). On a 7-point Likert scale, employees were asked to indicate the extent to which they agreed or disagreed with 
each of the items included in the measure $(1=$ strongly disagree; $7=$ strongly agree $)$. We conduct an explanatory factor analysis on the 7-item measure to generate a latent construct, GI. To demonstrate the validity of our survey instrument, we use the survey sample of 254 responses. ${ }^{13}$ Panel B of Appendix 3 presents the survey questions, the summary statistics of each item, and the factor loadings. It shows that the seven items load onto the same construct, and the average factor loading is about 0.86 . We find that the Cronbach's alpha (denoted by $\alpha$ ) of our construct is 0.95 , and the composite reliability is also higher than $0.90 .{ }^{14}$ Both statistics exceed the recommended threshold of 0.70 and indicate that the reliability of our survey instrument is sufficient. ${ }^{15}$

We also conduct construct validity tests using three measures that are expected to be significantly related to group identity (Ashforth and Mael 1989; Bergami and Bagozzi 2000; Hogg and Terry 2000). Based on prior research, employees tend to derive strong group identity if they believe that they receive high support from their group, and/or that they share similar goals and visions with other group members (Ashforth and Mael 1989; Eisenberger, Fasolo, and Davis-

\footnotetext{
${ }^{13}$ When estimating a latent variable using survey items, the number of the respondents is important. Previous research suggests that a minimum sample size of 200 should be sufficient to obtain a stable and accurate estimate in factor analysis (Hinkin 1998). Therefore, when generating the latent variable of group identity (GI), we include all respondents $(\mathrm{N}=254)$, including (but not limited to) the respondents from the three workgroups in our sample for this study $(\mathrm{N}=51)$.

${ }^{14}$ The Cronbach's alpha $(\alpha)$ represents the average inter-item correlation among items of a construct. Composite reliability is the squared sum of the standardized loadings divided by the aggregation of the squared sum of standardized loadings and the sum of the error variances on each item. Both statistics measure item interrelatedness by quantifying the proportion of the variance in the indicators that can be attributed to the underlying common source. If the items capture the same construct, they should be highly correlated (Lattin, Carrol, and Green 2003). The recommended threshold for both statistics is 0.70 (Bedford and Spekle 2018).

${ }^{15}$ Given that the Cronbach's alpha and composite reliability suggest our measure for group identity represents a unidimensional construct, we conduct a confirmatory factor analysis (CFA) to test the fit of a single-factor model. We find that compared with including all the seven items, removing the following three items increases the goodness of fit of the model: (a) when I talk about my group, I usually say 'we' rather than 'they'; (b) my group's successes are my successes; (c) being a member of my group is a major part of who I am. Based on our understanding about the setting, this may be because employees do not often use expressions like these in their daily life. Given the strong support for this measure in prior studies of group identity (e.g., Abernethy et al. 2017; Bergami and Bagozzi 2000; Boivie et al. 2011), we decide to retain all seven items. However, using the modified measure of group identity (i.e., a latent variable generated with the above three items removed) does not change the conclusion of our analyses. This additional analysis suggests that future research needs to carefully assess the psychometric properties of this measurement instrument when analyzing group identity in different settings.
} 
LaMastro 1990; Hogg 2006). Prior research also suggests that employees' group identity relates to the perceived overlap between their own and their group's image (Bergami and Bagozzi 2000; Boivie et al. 2011). In the survey, we measured employees' perceptions on the support they received from their workgroup, the shared goals with other group members, and the image overlap with their workgroup (Bergami and Bagozzi 2000; Boivie et al. 2011; Eisenberger et al. 1990; Hogg 2006). Panel C of Appendix 3 shows that, consistent with the predictions in previous research, our measure for group identity is significantly and positively correlated to these three variables ( $p<0.01$ for all variables). These results support the convergent validity of our group identity construct.

Further, we assess the discriminant validity of our group identity construct using $P M R S$, a latent variable that captures employees' perception about the informational and motivational effects of the performance measurement and reward system used in the SOE. Although employees who hold a positive view about the performance measurement and reward system adopted by their firm may also have a strong group identity, these two variables capture different theoretical constructs. In particular, the group identity variable $(G I)$ captures employees' self-concept where as PMRS captures employees' view about the effect of a control system adopted by their firm. We find that the correlation between the GI and PMRS $(\rho=0.33)$ is much lower than the correlations between $G I$ and the other two latent multi-item variables used in the convergent validity test (i.e., perceived support and shared goals). We also check the discriminant validity of GI by following the statistical test suggested by Fornell and Larcker (1981). Specially, we find that the average variance extracted (AVE) values of GI and PMRS (0.74 and 0.71, respectively) exceed the squared 
correlation between them $(0.55) .{ }^{16}$ This result provides support for the discriminant validity of our group identity construct.

\section{Performance Transparency (Transparent)}

The second independent variable, Transparent, is an indicator for high performance transparency. In our sample, the leader of one workgroup publicly discloses the performance information within his workgroup (i.e., performance transparency), whereas the leaders of the other two workgroups provide the performance information to each employee privately. Transparent is a dummy variable which indicates the observations from the group with high performance transparency. We also include the interaction term between Transparent and GI in our estimations, as it allows us to examine whether the relation between group identity and performance differs between workgroups with different levels of performance transparency.

\section{Performance Level (Performance)}

The dependent variable, Performance, is a proxy for employees' performance level. It is based on archival data that measures employees' operational actions, including the procedures and steps that employees take to inspect, operate, and maintain the equipment. The information about employees' operational actions is captured and recorded by the performance measurement and reward system of the SOE using two objective methods. First, when employees take some actions (e.g., adjusting the temperature or the pressure in the equipment), specialized machines which are connected to the equipment will automatically record these actions. Second, when taking actions that cannot be automatically recorded (e.g., conducting inspections in a certain area of the workshop), employees must tap their ID cards on machines located in the workshops, and the

\footnotetext{
${ }^{16}$ Discriminant validity can be demonstrated when the AVE value of a latent construct is larger than its squared correlation with another latent construct, showing that each of the constructs shares more variance with its associated indicators than with the other construct (Bedford and Spekle 2018).
} 
system will then record their actions.

There is considerable scope for employees to choose their effort level and actions. Most of the time, taking a certain set of routinized actions can keep the equipment functioning normally and help employees save effort. However, a more desired approach is to inspect and analyze the equipment carefully, identify and solve any hidden issues, and undertake the optimal operational actions based on the exact conditions of the equipment. This approach can reduce operational risks in the future, improve the efficiency of the equipment, and prolong its life. Employees have the discretion to save effort by following the routine, or exert higher effort and choose the more desired approach.

The upper level management links each operational action to a certain level of performance score, based on the importance of an action, as well as the effort required to undertake that action. At the end of every month, employees receive performance scores for the actions that they have taken in the past month. ${ }^{17}$ Our dependent variable, Performance, is the overall performance score each employee receives at the end of every month. It captures the effort that employees exerted when performing their tasks. The data of Performance is on a monthly basis, and the sample period is from January 2011 to July 2015.

\section{Performance Gap (PerGap)}

To examine employees' conformity, we construct a measure to capture the extent to which individual performance deviates from the performance "norm" within their workgroup. We call this deviation the "performance gap". Previous studies suggest that individuals perceive "norm"

\footnotetext{
${ }^{17}$ At the end of every month, employees receive a fixed payment and financial incentives. The fixed payment is linked to employees' position. The financial incentives are calculated based on the performance scores that employees received for the month, and account for approximately $0-10 \%$ of their overall compensation. The task design, performance measurement, score allocation, and compensation structure are pre-specified by the SOE and require little judgment from department managers or group leaders.
} 
as the behaviors of others around them (Cialdini and Trost 1998; Tayler and Bloomfield 2011). How employees perceive the performance norm of their workgroup is based on the information they received about others' performance. Following this intuition, we refer to the performance "norm" as the actual performance of employees within the same workgroup. When employees adjust their effort to conform to the group norm, the performance gap between their own performance and the group norm narrows (i.e., higher conformity).

We measure the group performance norm as the median employee performance within each group in the previous month. ${ }^{18}$ Specifically, for each month $t$ and each group $j$, we calculate the group's performance median based on employee performance in month $(t-1)$. We interpret this lagged performance median as the performance "norm" that employees under high performance transparency can observe from the previous period. We then calculate the absolute value of the difference between an employee $i$ 's performance and the perceived performance norm of his/her group $j$ at time $t$. We interpret this deviation as the degree of employees' performance gap, the inverse of their conformity:

$$
\text { PerGap }_{i t}=\mid \text { Performance }_{i t}-\text { Norm }_{j t}|=| \text { Performance }_{i t}-\text { Median }_{j(t-1)} \mid
$$

\section{Control Variables}

We controlled for a range of variables which may affect an employee's group identity and/or their task performance. The control variables include employees' skill level, which is assessed objectively by the SOE using work tests (Skill), the age of employees (Age), the number of years the employee has worked in the SOE (Tenure), an indicator for female employees (Gender),

\footnotetext{
${ }^{18}$ Our prediction about the conformity effect is that group identity motivates employees to conform to the performance of others in their group. Therefore, group median or mean is a reasonable empirical proxy that reflects the performance at the group level. The group median and mean are close in our setting. We tried using group mean to measure the performance gap and it does not change our conclusion. We use the lagged group median because the information about performance scores is organized and communicated to employees at the end of every month. Therefore, the performance reporting in month $(t-1)$ is the most recent and relevant reflection of the group norm.
} 
employees' education level $(E d u)$, an indicator for employees who come from the city where the SOE is located (Local), and an indicator for Chinese Communist Party members (Politics). ${ }^{19} \mathrm{We}$ also measure and control for employees' social connections (Referral) and family connections (Kinship) in the workplace, given these variables may affect employees' identity and performance (Beaman and Magruder 2012; Burks, Cowgill, Hoffman, and Housman 2015; Brown, Setren, and Topa 2016; Hensvik and Skans 2016). Additionally, we control for employees' perception of the performance measurement and reward system used in the SOE (PMRS), as it may affect employees' motivation and task performance (Hogg 2006; Steelman and Rutkowski 2004; Taylor and Pierce 1999). Moreover, in our setting, environmental factors such as weather and temperature may influence the condition of the equipment and employees' performance in certain months. We control for time fixed effects (i.e., the 55 months from January 2011 to July 2015) to address the potential influences of these factors. We also control for group fixed effects to address any timeinvariant differences between our sample groups. A detailed definition of each variable is provided in Appendix 4.

\section{Descriptive Statistics}

Panel A of Table 1 presents the descriptive statistics. The mean of employees' performance level (Performance) is 25.54, and its standard deviation is $15.34 .^{20}$ The performance gap (PerGap) has a slightly smaller sample size, as it is calculated using the lagged group median. The mean (median) of performance gap is $13.06(9.80)$. Table 1 also shows that the mean and median of group identity are 0.12 and 0.19 respectively, and its standard deviation is 0.46 . These statistics indicate that there is a degree of variation in employees' group identity in our sample. As for the

\footnotetext{
${ }^{19}$ Tenure is highly correlated with Age, so we keep Age in our set of control variables and drop Tenure in the estimations.

${ }^{20}$ We winsorized Performance at the 5th and 95th percentile, to make sure the results are not driven by the extreme values.
} 
control variables, the average skill level of the observations is 1.89 , which is between the medium (=1) and high (=2) levels set by the SOE. The average age of employees in our sample is 40.86 years old, and the average tenure is 21.59 years, indicating that most employees entered the SOE during the late 1980s and early 1990s. The difference between the average age and the average tenure is about 19 years. This is because most employees entered the organization immediately after graduating from high school or vocational school and have stayed in the organization for most of their working life. Nine percent of the employees have a short horizon (i.e., with five or less than five years to retire). Twenty-one percent of employees are female, and 57\% of employees came from the city where the SOE is located. Most employees graduated from senior high school or vocational school, and $17 \%$ are members of the Chinese Communist Party. Thirty-four percent of employees entered the SOE through referral, and $45 \%$ have family connections in the SOE.

Panel B of Table 1 compares the performance variation between different reporting choices. Specifically, the standard deviations of employee performance are 8.93 and 10.95 in groups with high and low performance transparency, respectively (difference $=-2.02, p<0.10$ ). This suggests that the variation of employee performance is significantly smaller when performance transparency is higher. In other words, employee performance is more homogeneous in the group with high performance transparency than in the groups with low performance transparency. These statistics are consistent with our prediction about the conformity effect of employees' group identity.

[Insert Table 1 Here]

\section{Correlations}

Table 2 provides the Pearson correlations between the variables. It shows that Performance is negatively correlated with Transparent, as well as group identity. The negative correlation between 
Performance and GI suggests that the relationship between the two variables is not straightforward and requires further analysis. Moreover, Performance is positively correlated with Skill, which we use as a proxy for ability. This is consistent with our assumption that employees with higher ability tend to have higher performance. Performance is also significantly correlated with most of the other control variables. PerGap is not significantly correlated with Transparent and group identity. Its correlations with the control variables are similar as those of Performance. Tenure is excluded from the estimations as it is highly correlated with Age; while other variables are not subject to severe multicollinearity issues.

[Insert Table 2 Here]

\section{EMPIRICAL MODELS AND RESULTS}

The interest alignment effect predicts a positive association between group identity and the level of employee performance. For the conformity effect, it is hard to generate a directional prediction on the level of employee performance, as employees may decrease or increase their effort to conform to others' performance. Instead, evidence of the conformity effect will be supported by a negative association between group identity and employees' performance "gap", i.e., the absolute value of the difference between an employee's performance and the lagged group median. We test the interest alignment and conformity effects of group identity in different empirical models, using employees' performance level (Performance) and performance gap (PerGap) respectively.

\section{Group Identity and Interest Alignment}

We examine the interest alignment effect by testing the association between employees' group identity and the level of their performance. We specify our empirical model as follows: 


$$
\begin{aligned}
\text { Performance }_{i t} & =\beta_{0}+\beta_{1} \text { GI }_{i}+\beta_{2} \text { Transparent }_{i}+\beta_{3}\left(\text { GI }_{i} \times \text { Transparent }_{i}\right)+\beta_{4} \text { Skill }_{i}+\beta_{5} \text { Age }_{i t} \\
& +\beta_{6} \text { Horizon }_{i t}+\beta_{7} \text { Gender }_{i}+\beta_{8} \text { Local }_{i}+\beta_{9} \text { Edu }_{i}+\beta_{10} \text { Politics }_{i}+\beta_{11} \text { Kinship }_{i} \\
& +\beta_{12} \text { Referral }_{i}+\beta_{13} \text { PMRS }_{i}+\varepsilon_{i t}
\end{aligned}
$$

The dependent variable, Performance $i$, is employee $i$ 's performance during month $t$. The independent variables include employees' group identity $(G I)$, the binary variable indicating performance transparency (Transparent), and their interaction (GI× Transparent). In the groups with low performance transparency, the association between group identity and performance is captured by the main effect of group identity $\left(\beta_{1}\right)$. In the group with high performance transparency, this association is represented by the joint effect of $G I$ and Transparent $\left(\beta_{1}+\beta_{3}\right)$. The difference induced by performance transparency is captured by the coefficient of the interaction term $\left(\beta_{3}\right)$. $\mathrm{H} 1$ predicts that group identity is associated with higher performance levels (i.e., higher interest alignment) in groups with low performance transparency than in the group with high performance transparency. In other words, we expect that the association between group identity and employee performance level is more positive when performance transparency is low than when it is high (i.e., $\left.\beta_{3}<0\right)$.

We control for factors that could explain the variations in employee performance. In Model (1), we control for individual characteristics that may affect employee performance including employees' ability (e.g., Skill), social connections (e.g., Local, Kinship, Politics, and Referral), implicit incentives (e.g., Horizon), and other personal characteristics (e.g., Age and Gender). We also control for employees' view of the performance measurement and reward system (PMRS) adopted at the research site, as it may affect employees' motivation and performance (Steelman and Rutkowski 2004; Taylor and Pierce 1999). As our panel dataset includes multiple individuals and time periods, the performance observations of each individual may relate to each other. We 
employed a random-effect model and have the standard errors clustered at the individual level to address this issue. Furthermore, we control for group fixed effects and time fixed effects to address any unobserved group or time effects on employee performance. ${ }^{21}$

Table 3 presents the results of Model (1). Columns (1) and (2) show the results estimated using the full sample. Column (1) shows that, without considering the moderating role of performance transparency, there is no significant association between employees' group identity and their performance level. In Column (2), we allow the association to vary between groups with high and low performance transparency. We find that group identity is positively associated with the level of employee performance when performance transparency is low $\left(\beta_{1}=5.93, t=2.72\right)$. We also find that the coefficient of the interaction term is negative and significant $\left(\beta_{3}=-12.32, t=-3.98\right)$. These results suggest that when performance transparency is low (high), employees' group identity is positively (negatively) associated with their performance level. Consistent with H1, our results suggest that group identity is associated with higher performance levels when performance transparency is low than when it is high.

We also conduct a subsample analysis which allows the coefficients of all variables to vary between different performance reporting choices. The results are presented in Columns (3) and (4). This subsample analysis confirms the results provided in Column (2). Specifically, Column (3) Shows that when performance transparency is low, employees' group identity is positively associated with their performance level $\left(\beta_{1}=4.87, t=1.87\right)$. In contrast, Column (4) shows that when performance transparency is high, employees' group identity is negatively associated with

\footnotetext{
${ }^{21}$ In our setting, different performance scores apply in different situations (e.g., follow certain steps in the daily routine, handle special situations in extreme weather, detect a hidden problem). Although the aggregation of scores for all situations is 130, no one can possibly encounter all the situations and earn the "full score" within a certain month. The descriptive statistics also indicate that the maximum value of Performance is within this range. In other words, the dependent variable is not truly censored and using Tobit regressions is thus not necessary (Angrist and Pischke 2009). We tried Tobit regressions as a robustness check, the results of which are similar as those of OLS, so our conclusions remain the same.
} 
the level of their performance $\left(\beta_{1}=-6.19, t=-3.10\right)$. We compare the coefficients of Columns (3) and (4) and find that the difference is significant $(z=3.36, p<0.01)$. These results suggest that, consistent with our expectation, the association between employees' group identity and performance level varies between groups with different performance reporting choices.

Overall, the findings presented in Table 3 are consistent with our first hypothesis (H1), which predicts that the interest alignment effect of group identity is more salient when performance transparency is low than when it is high. We only find a positive association between group identity and performance in groups with low performance transparency. In the group with high performance transparency, we find that group identity is negatively associated with employee performance. Our evidence not only suggests that the effect of group identity on employee performance depends on managers' performance reporting choice, but also highlights that group identity could cause adverse performance consequences when performance information is transparent.

\section{[Insert Table 3 Here]}

\section{Group Identity and Conformity}

We next examine the conformity effect of group identity by testing its association with employees' performance gap. We specify our empirical model as follows:

$$
\begin{aligned}
\text { PerGap }_{i t} & =\beta_{0}+\beta_{1} \text { GI }_{i}+\beta_{2} \text { Transparent }_{i}+\beta_{3}\left(\text { GI I }_{i} \times \text { Transparent }_{i}\right)+\beta_{4} \text { Skill }_{i}+\beta_{5} \text { Ageit } \\
& +\beta_{6} \text { Horizon }_{i t}+\beta_{7} \text { Gender }_{i}+\beta_{8} \text { Local }_{i}+\beta_{9} \text { Edu }_{i}+\beta_{10} \text { Politics }_{i}+\beta_{11} \text { Kinship }_{i} \\
& +\beta_{12} \text { Referral }_{i}+\beta_{13} \text { PMRS }_{i}+\varepsilon_{i t}
\end{aligned}
$$

The dependent variable in Model (2) is the gap between employees' individual performance and the performance norm in their group (PerGap). The independent variables include employees' group identity $(G I)$ and the indicator for performance transparency (Transparent). To test whether 
the conformity effect of group identity is more salient when performance transparency is high $($ Transparent $=1)$ than when it is low (Transparent $=0)$, we include an interaction term between group identity and Transparent. H2 predicts that group identity is associated with smaller performance gaps (i.e., higher conformity) when performance transparency is high than when it is low. In other words, we expect the interaction term between group identity and the indicator for performance transparency to be negative (i.e., $\beta_{3}<0$ ).

In Model (2), we include the employees' individual characteristics defined in Model (1) to control for their potential effects on employee performance and thus, the performance gap. We also control for group and time fixed effects, as well as individual random effects, in order to address any unobserved group, time, and individual effects. Same as Model (1), we have the standard errors clustered at employee level when estimating Model (2) to address the potential heteroscedasticity in the panel dataset.

The results of Model (2) are presented in Table 4. Columns (1) and (2) present the estimated coefficients using the full sample. Our interpretations are based on Column (2), in which the interaction term is included to test the conformity effect in groups with different performance reporting choices. It shows that the coefficient on the interaction between group identity and Transparent is significantly negative $\left(\beta_{3}=-7.15, t=-3.46\right)$. In other words, group identity is associated with a smaller performance gap (i.e., higher conformity) when performance transparency is high than when it is low. This evidence is consistent with H2.

Further, we estimate Model (2) using the subsamples of different performance reporting choices. The results are presented in Columns (3) and (4). Column (3) reports the coefficients estimated using the groups with low performance transparency. The positive coefficient for group identity $\left(\beta_{1}=3.30, t=2.15\right)$ indicates that when performance transparency is low, group identity 
is associated with a larger performance gap, i.e., lower conformity. However, Column (4) presents the results of the group with high performance transparency and reports a negative association between group identity and performance gap $\left(\beta_{1}=-2.47, t=-1.79\right)$. In other words, group identity is associated with greater conformity when performance transparency is high. We also find that the coefficient for group identity in Column (3) is statistically different from that in Column (4) ( $z$ $=2.80, p<0.01)$.

Taken together, the results presented in Table 4 are consistent with our expectation in $\mathrm{H} 2$ that the association between group identity and performance gap is conditional on the level of performance transparency. When employees receive information about others' performance, those with strong group identity adjust their effort to conform to the group performance norm. However, this pattern does not exist when employees only receive information about their own performance. Our evidence demonstrates the conformity effect of group identity, which is salient when performance transparency is high.

\section{[Insert Table 4 Here]}

\section{Does the Direction of Conformity Differ between High- and Low-Ability Employees?}

We conduct additional analyses to shed light on the direction of the conformity effect of group identity. Some employees may conform to the performance norm of their group by withholding effort (downward conformity) and others may conform by working harder (upward conformity). We expect that when employees have strong group identity, those with high (low) ability are more likely to exhibit downward (upward) conformity. In our setting, skill level (Skill) of employees is regularly assessed by the SOE using work-skill tests, and it reflects employees' ability in analyzing the equipment conditions and choosing the appropriate actions. We thus use Skill as a proxy for employees' ability. Using regular exams, the SOE divides employees into four levels $(0=$ low; 1 
$=$ medium; $2=$ high; $3=$ excellent). ${ }^{22}$ We use these levels to divide our sample into high-ability $($ Skill $=2$ or 3$)$ and low-ability (Skill $=0$ or 1$)$, and estimate the relation between group identity and performance within each subsample using Model (1) ${ }^{23}$ We predict that in the group with high performance transparency, group identity is negatively associated with the performance of highability employees (i.e., downward conformity), but positively associated with the performance of low-ability employees (i.e., upward conformity).

Table 5 presents our results of estimating Model (1) using the subsamples. Columns (1) and (2) present the estimates for low- and high-ability employees under high performance transparency, respectively. In Column (1), we find a positive coefficient for group identity $\left(\beta_{1}=\right.$ $31.01, t=9.15$ ), suggesting that group identity is associated with higher performance (i.e., upward conformity) for low-ability employees. However, Column (2) reports a negative coefficient for group identity $\left(\beta_{1}=-8.40, t=-3.07\right)$, indicating that group identity is associated with lower performance (i.e., downward conformity) for high-ability employees. We also find that the difference between the coefficients in Columns (1) and (2) is significant $(z=-11.32, p<0.01)$. In sum, the results suggest that group identity's effect on performance depends on employees' ability level. Note that these findings are specific to the group with high performance transparency, where the conformity effect is activated. We conduct the same analysis in the groups where performance transparency is low. The results are presented in Columns (3) and (4) and do not show similar conformity patterns. Overall, the results presented in Table 5 provide further support for $\mathrm{H} 2$, which

\footnotetext{
${ }^{22}$ The test is in the format of questions designed to assess the skill sets of employees operating different types of equipment. The skill test is organized by the SOE every three years, and all the front-line employees are required to take it. Employees who passed the test are assigned with a skill level based on their performance in the test. Those who failed the test are required to do trainings. The skill level used in our study was assessed based on the test held in 2012, and none of the employees in our sample failed.

${ }^{23}$ Besides using Skill, we also employed an alternative measure for employees' ability, which is based on their actual performance during the sample period. Within each workgroup, we divided employees into four quantiles based on their monthly performance and classify them as high-ability and low-ability based on the quantile that they fall into most frequently. The conclusion remains the same when using this alternative measure for employee ability.
} 
predicts that the conformity effect is more salient when performance transparency is high than when it is low.

\section{[Insert Table 5 Here]}

Taken together, our empirical results document a positive association between group identity and performance in groups where performance information is communicated to employees privately. This is consistent with our prediction about the interest alignment effect of group identity (H1). Our results also indicate that in the group where performance information is transparent among employees, group identity is negatively (positively) associated with the performance of high-(low-) ability employees. This evidence is consistent with our prediction about the conformity effect (H2). Overall, these results are consistent with our prediction that the association between employees' group identity and their performance is conditional on the performance transparency in the workplace.

\section{Robustness Checks}

We conduct a range of analyses to check the robustness of our findings. First, we winsorized the performance variable in our main analyses. In the robustness check, we find that using the unwinsorized performance data as the dependent variable does not change our conclusion. Second, we use the lagged group median to calculate the performance gap variable in our main analyses. As a robustness check, we use the lagged group mean to calculate performance gap and find similar results as in the main analyses. Third, the dependent variable in our main analyses (i.e., monthly performance of employees) is time-variant whereas most of the explanatory variables (e.g., employees' group identity) are time-invariant. As a robustness check, we conduct a between-effect analysis which estimates the coefficient of group identity using the cross-sectional information in our panel dataset. The results of the between-effect analysis are consistent with our main findings. 
Additionally, we assume that the variation of employees' group identity is stable across our sample period. As a robustness check, we "relax" this assumption by reducing our sample to the year of 2015 only (i.e., the year when employees' group identity was assessed). When using this reduced sample, we reach the same conclusion as the main analyses.

\section{Additional Analysis - Determinants of Group Identity}

Besides testing our hypotheses, we also explore which variables may affect group identity in our setting. The objective of this analysis is twofold. First, our study is based on the argument that performance transparency moderates the relation between group identity and performance. However, an alternative argument is that group identity mediates the association between performance transparency and employee performance. We address the alternative argument by examining whether performance transparency affects employees' group identity. Second, we are interested in whether employees' demographic background or perception about the control environment in their workplace are associated with their group identity. Although not directly relating to our research question, findings about this question may provide important insight to future research.

We regress group identity on the indicator for performance transparency, as well as a range of other variables, using both the research and the survey samples. Table 6 presents the results. We find that employees' group identity is not significantly associated with the indicator for high performance transparency (Transparent) in either of the two samples. Instead, group identity is significantly associated with whether employees have family members in the organization (Kinship) and their perception about the control system adopted in the organization (PMRS). In some of the regressions, group identity is also significantly associated with employees' time horizon (Horizon) and their political affiliation (Politics). Overall, this additional analysis rules 
out the possibility that group identity mediates the association between performance transparency and employee performance. Further, the results suggest that employees' group identity may be influenced by their connections with the company (Kinship, Horizon, and Politics), and is associated with their perception about the existing control system (PMRS). Particularly, the variable PMRS captures employees' perception about the motivation and information effects of the performance measurement and reward system adopted by the SOE. Based on this finding, future research may investigate how formal control mechanisms (e.g., performance measures and incentives) influence the social controls (e.g., group identity) in organizations.

[Insert Table 6 Here]

\section{CONCLUDING REMARKS}

Using archival and survey data from a field site, we find that the association between employees' group identity and their task performance is conditional on performance transparency in the workplace. We find that when employees only receive information about their own performance, group identity is positively associated with employee performance. In contrast, when employees receive information about their own and their group members' performance, group identity is negatively (positively) associated with the performance of high-(low-) ability employees. Our findings extend prior research by demonstrating that performance transparency plays an important role in activating the two different effects of group identity; that is, the interest alignment effect is activated when there is low performance transparency, while the conformity effect is activated when there is high performance transparency.

Our study adds to the growing literature which examines the role of identity in organizations (e.g., Abernethy et al. 2017; Boivie et al. 2011; Heinle, Hofmann, and Kunz 2012; Towry 2003). Our findings document the benefits as well as the potential costs of encouraging group identity in 
organizations. Further, our findings contribute to the literature on the "hidden costs" of control (e.g., Cardinaels and Yin 2015; Hannan et al. 2013; Maas and Yin 2018), by demonstrating that a more transparent performance reporting choice can interact with employees' group identity and lead to negative behavioral outcomes. Our findings suggest that managers need to consider employees' group identity and ability, as well as the performance distribution in their groups when making decisions regarding internal performance reporting.

Our study has several potential limitations. First, to examine our research question, we used a field site where employees' group identity is salient and there is a variation in performance transparency across different groups. It is an open question as to what extent we can generalize the findings from a single research site. Prior research suggests that conformity is more pronounced and individuals are more likely to see themselves as part of a group in a collectivistic culture (e.g., China) than in an individualistic culture (Bond and Smith 1996; Kim and Markus 1999). ${ }^{24}$ That is, employees' group identity and tendency to conform may be higher in our setting than in firms with a different cultural background. However, evidence also suggests that conformity is not a unique feature of collective cultures. Instead, it exists and can be salient in individualistic cultures as well (e.g., Cialdini and Trost 1998; Bandiera et al. 2010). Further, even if group identity and conformity were more pronounced in our setting than in other firms, we still find a variation in employees' group identity and that group identity is associated with different employee behaviors in groups with different levels of performance transparency. While our setting enables us to control the potential influences of contextual factors (e.g., culture, task nature, operating environment), future research could extend our findings by studying group identity across different firms or cultures.

\footnotetext{
${ }^{24} \mathrm{We}$ also considered the influence of Confucianism in China. We find that the link between Confucianism and conformity is through its collectivistic nature (Bloom, Martin, and Proudfoot 1996; Romar 2002). In other words, the discussion comes back to collectivistic versus individualistic cultures.
} 
Further, different types of norms may develop in different settings. Future research may also examine the performance implications of conforming to different norms.

Second, our study is potentially subject to reverse causality and omitted-variable concerns. We attempt to address the reverse causality between group identity and performance using a simultaneous equations model. ${ }^{25}$ However, we cannot fully rule out this concern using a fieldbased dataset and a "snapshot" measure of group identity. Additionally, given that the groups in our sample are not randomly assigned, we cannot completely rule out the potential influences of correlated omitted variables (e.g., unobserved employee characteristics). However, given that we select comparable workgroups within the same department as the research sample and that group leaders in our setting do not have decision rights to change the existing control mechanisms or implement new ones, the potential issue of omitted variables is unlikely to be a significant threat to our study. Finally, although this study documents the association between group identity and employee performance in groups with different levels of performance transparency, we cannot (and do not attempt to) demonstrate the causal chain that explains these associations using field data from our research site. Future research could attempt to replicate and extend this study in a setting that reduces the effects of these potential limitations.

\footnotetext{
${ }^{25}$ We develop simultaneous equations about group identity and employee performance based on the method used in Nagar (2002). We find group identity is a significant explanatory variable in the model of performance, but performance is not a significant explanatory variable in the model of group identity. That is, employees' group identity is likely to influence their performance, but not the other way around. The model specification and results are available from the authors.
} 
Appendix 1.

Performance Reporting Choices at the Research Site

Groups with Low Performance Transparency

\begin{tabular}{|c|c|c|c|c|}
\hline & item1 & item2 & $\ldots$ & overall \\
\hline A & \multicolumn{5}{|l|}{} \\
\hline & item1 & item2 & $\ldots$ & overall \\
\hline B & \multicolumn{1}{|c|}{} & & \\
\hline & item1 & item2 & $\ldots$ & overall \\
\hline C & & & & \\
\hline & item1 & item2 & $\ldots$ & overall \\
\hline $\mathrm{n}$ & & & & \\
\hline
\end{tabular}

Each employee receives a note with his/her performance only. Employees can only see their own names on the note.

Groups with High Performance Transparency

\begin{tabular}{|c|c|c|c|c|}
\hline & item1 & item2 & $\ldots$ & overall \\
\hline A & & & & \\
\hline B & & & & \\
\hline C & & & & \\
\hline$\ldots$ & & & & \\
\hline$n$ & & & & \\
\hline
\end{tabular}

Employees pass around the performance table that presents everyone's name and performance. 
Appendix 2.

Structure of Workgroups Used as Research Sample

Panel A: Structure of the Groups used as Research Sample

\begin{tabular}{lcccc}
\hline \hline & Overall & Group 1 & Group 2 & Group 3 \\
\hline Transparency & NA & Low & Low & High \\
\cline { 2 - 5 } Group size & NA & 31 & 30 & 33 \\
Skill & 1.64 & 1.61 & 1.65 & 1.68 \\
Age & 43.29 & 43.56 & 42.41 & 43.81 \\
Tenure & 23.33 & 23.80 & 22.48 & 23.64 \\
Gender & 0.28 & 0.29 & 0.37 & 0.18 \\
Local & 0.54 & 0.45 & 0.57 & 0.61 \\
Edu & 0.99 & 1.10 & 0.97 & 0.91 \\
Politics & 0.16 & 0.13 & 0.07 & 0.27 \\
\hline
\end{tabular}

Appendix 2 presents the structure of the three workgroups used as the research sample. Transparency indicates whether a group has low or high performance transparency. Group size refers to the number of employees. Skill is employees' skill levels; which are assigned by the organization using work tests. Age and tenure are employees' age and the number of years that they have worked in the research site, respectively. Gender is an indicator for female employees. Local is an indicator for employees who come from the city where the research site is located. $E d u$ is the education level of employees, which equals to 0 for junior high school or equivalent, 1 for senior high school or equivalent, 2 for undergraduate degree, or 3 for postgraduate degree and higher. Politics is an indicator for employees who are members of the Chinese Communist Party. 


\section{Appendix 3. \\ Descriptive Statistics of Survey Respondents and Constructs}

Panel A: Respondents versus Non-respondents in the Sample Groups

\begin{tabular}{lcccc}
\hline \hline & $\begin{array}{c}\text { Non-respondents } \\
(\mathrm{N}=43)\end{array}$ & $\begin{array}{c}\text { Respondents } \\
(\mathrm{N}=51)\end{array}$ & Difference & t-statistics \\
\cline { 2 - 5 } Age & 42.74 & 42.88 & -0.15 & -0.11 \\
Tenure & 23.56 & 23.66 & -0.10 & -0.07 \\
Gender & 0.32 & 0.24 & 0.08 & 0.84 \\
Local & 0.53 & 0.57 & -0.04 & -0.39 \\
Edu & 0.92 & 0.98 & -0.06 & -0.42 \\
Politics & 0.11 & 0.18 & -0.07 & -0.93 \\
\hline
\end{tabular}

Panel A compares the demographic characteristics of survey respondents $(\mathrm{N}=51)$ and non-respondents $(\mathrm{N}=43)$ in the sample workgroups employed by this study. Age and tenure are employees' age and the number of years that they have worked in the research site, respectively. Gender is an indicator for female employees. Local is an indicator for employees who come from the city where the research site is located. $E d u$ is the education level of employees, which equals to 0 for junior high school or equivalent, 1 for senior high school or equivalent, 2 for undergraduate degree, or 3 for postgraduate degree and higher. Politics is an indicator for employees who are members of the Chinese Communist Party. None of the differences are statistically significant. 
Appendix 3.

Descriptive Statistics of Survey Respondents and Constructs (cont.)

Panel B: Survey Questions, Summary Statistics, and Loadings on Group identity $(N=254)$

\section{Group Identity ${ }^{\mathrm{a}}(\alpha=0.95)^{\mathrm{b}}$}

When someone criticizes my group, it feels like a personal insult. I am very interested in what others think about my group.

When I talk about my group, I usually say 'we' rather than 'they'.

My group's successes are my successes.

When someone praises my group, it feels like a personal compliment.

If my group was criticized by someone outside my group, I would feel embarrassed.

Being a member of my group is a major part of who I am.

\begin{tabular}{ccc} 
Mean & s.d. & $\begin{array}{c}\text { Factor } \\
\text { loadings }\end{array}$ \\
\hline 5.79 & 1.30 & 0.86 \\
5.74 & 1.28 & 0.78 \\
6.05 & 0.94 & 0.78 \\
5.62 & 1.34 & 0.86 \\
5.78 & 1.21 & 0.93 \\
5.73 & 1.23 & 0.91 \\
5.88 & 1.03 & 0.88
\end{tabular}

\section{Constructs Used to Test the Construct Validity of Group Identity \\ Image Overlap}

Please indicate to what degree your self-image overlaps with your group's image.

(Answers ranging from 1 [does not overlap at all] to 7 [fully overlaps])

$5.73 \quad 1.27 \quad$ NA

Imagine that one of the circles on the left represents you and the circle on the right represents your group. Please indicate which case best describes the level of overlap between you and your group. ${ }^{\mathrm{c}}$

$\begin{array}{lll}6.36 & 1.7 \quad \mathrm{NA}\end{array}$

Perceived support from workgroup $(\alpha=0.95)$

My group values my contributions.

$6.36-1.7-\mathrm{NA}$

My group appreciates any extra effort from me.

$\begin{array}{lll}5.64 & 1.26 & 0.92\end{array}$

My group really cares about my wellbeing.

$5.63 \quad 1.31$

0.93

Shared goals with other group members $(\alpha=0.91)$

$\begin{array}{lll}5.67 & 1.29 & 0.90\end{array}$

My group members and I always agree on what is important at work.

$\begin{array}{lll}5.76 & 1.12 & 0.87\end{array}$

My group members and I always share the same ambitions and vision at work.

$5.56 \quad 1.22$

0.87

(continued.) 
Appendix 3.

Descriptive Statistics of Survey Respondents and Constructs (cont.)

Panel B: Survey Questions, Summary Statistics, and Loadings on Group identity (cont.)

\section{Perception about the PMRS adopted in the organization ( $\alpha=0.96)$}

The performance bonus helps me understand how I can do my job better.

The performance bonus helps me better understand the expectations of my superiors.

I learn a lot from the performance bonus I received.

\begin{tabular}{llc} 
Mean & s.d. & $\begin{array}{c}\text { Factor } \\
\text { loadings }\end{array}$ \\
\hline
\end{tabular}

The performance bonus I received makes me want to improve my

performance.

After receiving performance bonuses, I will work extra hard on my tasks.

The performance bonus motivates me to try my best when doing my tasks.

\begin{tabular}{lll}
\hline 5.52 & 1.42 & 0.92 \\
5.48 & 1.38 & 0.91 \\
5.57 & 1.27 & 0.92 \\
5.56 & 1.30 & 0.88 \\
5.68 & 1.15 & 0.87 \\
5.72 & 1.14 & 0.86 \\
\hline
\end{tabular}

Panel B of Appendix 3 presents the constructs used to measure employees' group identity, as well as the constructs used to test the construct validity of group identity. All items on identity and perception are measured on a seven-point Likert scale $(1=$ strongly disagree; $7=$ strongly agree), unless stated otherwise. The Chinese version of the survey was sent to 445 employees in four departments of the SOE in May 2015; 254 employees responded (response rate $=57 \%$ ).

a. The survey questionnaires sent to the employees did not include the subtitles. The subtitles are used here to present and distinguish different instruments.

b. Cronbach's alpha, denoted by $\alpha$, indicate the internal consistency reliability of multi-item scales.

c. This question asks the respondents to choose one of the visual expressions that can best describe the overlap between their own and their workgroup's image. The visual expression is as follows:

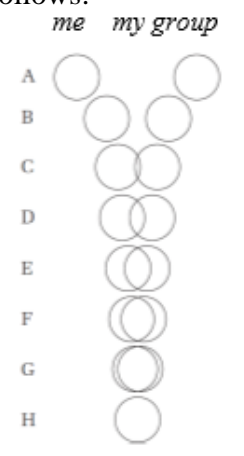




\section{Appendix 3. \\ Descriptive Statistics of Survey Respondents and Constructs (cont.)}

Panel C: Correlations between Group Identity (GI) and Other Constructs

\begin{tabular}{lc} 
& \\
\hline \hline & $G I$ \\
Perceived support from workgroup & $0.71^{* * *}$ \\
Shared goals with other group members & $0.64^{* * *}$ \\
Image Overlap & $0.57^{* * *}$ \\
Image Overlap (visual expression) & $0.46^{* * *}$ \\
Perception about PMRS & $0.33^{* * *}$ \\
\hline
\end{tabular}

Panel C of Appendix 3 presents the results of the construct validity tests, which examine the correlations between the latent variable of group identity $(G I)$ and three variables (perceived support, shared goals, and image overlap) which capture similar theoretical constructs as group identity. It also presents the correlation between $G I$ and a variable (PMRS) which captures a different theoretical construct as group identity. *,**,** indicates significance at the $10 \%, 5 \%$ and $1 \%$ levels, respectively. 
Appendix 4.

Variable Definitions

Performance scores that employees receive at the end of every month for the actions they took to inspect, operate, and maintain the equipment. Employees' actions are captured by the specialized Performance machines located in the workshops. At the end of every month, employees receive performance scores for the actions that they have taken in the past month. These scores capture the effort level of employees when performing their tasks.

\begin{tabular}{ll}
\hline PerGap & $\begin{array}{l}\text { The absolute value of the difference between employee } i \text { 's performance in month } t \text { and the group norm } \\
\text { (i.e., the group median from the previous period, } t-1 \text { ) in her workgroup } j .\end{array}$ \\
\hline $\boldsymbol{G I}$ & $\begin{array}{l}\text { Employees' group identity, latent variable measured using survey questions (details presented in } \\
\text { Appendix 3). }\end{array}$ \\
Transparent & $\begin{array}{l}\text { Coded } 1 \text { for observations from the workgroup where performance transparency is high (i.e., the group } \\
\text { leader publicly discloses performance information within his workgroup), and } 0 \text { for observations from } \\
\text { the workgroups where performance transparency is low (i.e., the group leaders privately provide } \\
\text { performance information to each employee in their workgroup). }\end{array}$ \\
\hline
\end{tabular}

Employees' skill level; assessed by the SOE through work tests. Every three years, the SOE holds a test to assess employees' operational skills, and assigns skill levels to employees based on their test Skill results. There are four skill levels: 0 (low), 1 (medium), 2 (high), and 3 (excellent). To achieve a particular level, employees must achieve a certain score in the test. In this study, the variable Skill is the skill level assigned by the SOE at the end of 2012.

\begin{tabular}{|c|c|}
\hline Age & $\begin{array}{l}\text { Employee } i \text { 's age; calculated using employee } i \text { 's date of birth and the dates that } i \text { received his or her } \\
\text { performance score. }\end{array}$ \\
\hline Tenure & $\begin{array}{l}\text { Number of years that employee } i \text { has been working in the SOE, calculated using employee } i \text { 's date of } \\
\text { entry, and the dates that } i \text { received his or her performance score. }\end{array}$ \\
\hline Horizon & $\begin{array}{l}\text { Equal to } 1 \text { for male workers over } 49 \text { and female workers over } 44 \text { (i.e., } 5 \text { years before retirement), and } \\
0 \text { otherwise. }\end{array}$ \\
\hline Gender & Equal to 1 for employees who are female, and 0 otherwise. \\
\hline Local & $\begin{array}{l}\text { Equal to } 1 \text { for employees recruited from the city where our research site is located, and } 0 \text { for employees } \\
\text { recruited from other regions of China. }\end{array}$ \\
\hline Edu & $\begin{array}{l}\text { Education level of an employee, taking the value } 0 \text { for junior high school or equivalent, } 1 \text { for senior } \\
\text { high school or equivalent, } 2 \text { for undergraduate degree, or } 3 \text { for postgraduate degree and higher. }\end{array}$ \\
\hline Politics & Equal to 1 for employees who are members of the Chinese Communist Party, and 0 otherwise. \\
\hline Kinship & $\begin{array}{l}\text { The proxy for employees who have kinship(s) in the research site. Measured by one survey question: } \\
\text { Do you have any family (including spouse, parent [s], offspring[s] and/or other family members) who } \\
\text { also work in the SOE? ( } 1=\text { Yes, I have family who also work[s] in the SOE; } 2=I \text { used to have but } \\
\text { they left the SOE; } 3=\text { No, I never had any family working in the SOE). Equals to } 1 \text { for employees who } \\
\text { answered " } 1=\text { Yes, I have family who also work[s] in the SOE", and } 0 \text { otherwise. }\end{array}$ \\
\hline Referral & $\begin{array}{l}\text { The proxy for employees who entered into the SOE through the recommendation of existing } \\
\text { employees. Measured through two survey questions: (1) How did you enter the SOE? }(1=\text { allocated } \\
\text { by the government; } 2 \text { through another channel); (2) Before entering the SOE, did you have any } \\
\text { relative/friend/acquaintance in the SOE? }(1=\text { Yes; } 2=\text { No). Equals to } 1 \text { for employees who were not } \\
\text { allocated by the government and had connections with existing employees before entering the SOE, } \\
\text { and } 0 \text { otherwise. }\end{array}$ \\
\hline PMRS & $\begin{array}{l}\text { Employees' perception on the performance measurement and reward system adopted in the research } \\
\text { site. Measured by survey questions about the perceived information and motivation effects of the } \\
\text { SOE's performance measurement and reward system. The questions are designed based on prior } \\
\text { studies (Steelman and Rutkowski 2004; Taylor and Pierce 1999). Details about the questions are } \\
\text { presented in Appendix 3. }\end{array}$ \\
\hline
\end{tabular}




\section{REFERENCES}

Abernethy, M., J. Bouwens, and P. Kroos. 2017. Organization identity and earnings manipulation. Accounting, Organizations and Society 58: 1-14.

Akerlof, G. A., and R. E. Kranton. 2000. Economics and identity. Quarterly Journal of Economics 115: 715-753.

Akerlof, G. A., and R. R. Kranton. 2005. Identity and the Economics of Organizations. Journal of Economic Perspectives 19 (1): 9-32.

Akerlof, G. A., and R. E. Kranton. 2010. Identity Economics: How Our Identities Shape Our Work, Wages, and Well-Being. Princeton, NJ: Princeton University Press.

Angrist, J. D., and J. S Pischke. 2009. Mostly harmless econometrics: An empiricist's companion. Princeton, NJ: Princeton University Press.

Ashforth, B. E., and F. Mael. 1989. Social identity theory and the organization. Academy of Management Review 14: 20-39.

Bandiera, O., I. Barankay, and I. Rasul. 2005. Social preferences and the response to incentives: Evidence from personnel data. The Quarterly Journal of Economics 120 (3): 917-962.

Bandiera, O., I. Barankay, and I. Rasul. 2010. Social incentives in the workplace. The Review of Economic Studies 77 (2): 417-458.

Baron, J., and D. Kreps. 1999. Strategic human resources: Frameworks for general managers. New York, NY: John Wiley \& Sons, Inc.

Bartel, C. 2001. Social comparisons in boundary-spanning work: Effects of community outreach on members' organizational identity and identification. Administrative Science Quarterly 46: 379-413.

Beaman, L., and J. Magruder. 2012. Who gets the job referral? Evidence from a social network experiment. The American Economic Review 102: 3574-3593.

Bedford, D. S., and R. F. Speklé. 2018. Construct validity in survey-based management accounting and control research. Journal of Management Accounting Research 30 (2): 23-58.

Benjamin, D. J., J. J. Choi, and A. J. Strickland. 2010. Social identity and preferences. American Economic Review 100 (4): 1913-28.

Bergami, M., and R. P. Bagozzi. 2000. Self-categorization, affective commitment and group selfesteem as distinct aspects of social identity in the organization. British Journal of Social Psychology 39: 555-577.

Blader, S., C. M. Gartenberg, and A. Prat. 2016. The contingent effect of management practices. Columbia Business School Research Paper 15-48.

Bloom, I., J. P. Martin, and W. L. Proudfoot. "Confucian perspectives on the individual and the collective." Religious Diversity and Human Rights, edited by Irene Bloom. New York: Columbia University Press, 1996, pp.114-151.

Boivie, S., D. Lange, M. L McDonald, and J. D. Westphal. 2011. Me or we: The effects of CEO organizational identification on agency costs. Academy of Management Journal 54: 551576.

Bol, J. C., S. Kramer, and V. S. Maas. 2016. How control system design affects performance evaluation compression: The role of information accuracy and outcome transparency. Accounting, Organizations and Society 51: 64-73.

Bond, R., and P. B. Smith. 1996. Culture and conformity: A meta-analysis of studies using Asch's (1952b, 1956) line judgment task. Psychological Bulletin 119 (1): 111-137. 
Brown, M., E. Setren, and G. Topa. 2016. Do informal referrals lead to better matches? Evidence from a firm's employee referral system. Journal of Labor Economics 34: 161-209.

Burks, S. V., B. Cowgill., M. Hoffman, and M. Housman. 2015. The value of hiring through employee referrals. The Quarterly Journal of Economics 130: 805-839.

Cardinaels, E., and H. Yin. 2015. Think twice before going for incentives: Social norms and the principal's decision on compensation contracts. Journal of Accounting Research 53: 9851015.

Chen, Y., and S. X. Li. 2009. Group identity and social preferences. The American Economic Review 99: 431-57.

Cialdini, R. B., and M. R. Trost. 1998. Social influence: Social norms, conformity, and compliance. In The Handbook of Social Psychology, Volume II, edited by D. T. Gilbert, S. T. Fiske, and G. Lindzey, 151-192. New York, NY: Oxford University.

Cialdini, R. B., and N. J. Goldstein. 2004. Social influence: Compliance and conformity. Annual Review of Psychology 55: 591-621.

Dukerich, J. M., B. R. Golden, and S. M. Shortell. 2002. Beauty is in the eye of the beholder: The impact of organizational identification, identity, and image on the cooperative behaviors of physicians. Administrative Science Quarterly 47: 507-533.

Eisenberger, R., P. Fasolo, and V. Davis-Lamastro. 1990. Perceived organizational support and employee diligence, commitment, and innovation. Journal of Applied Psychology 75: 5159.

Eyring, H. and V. G. Narayanan. 2018. Performance Effects of Setting a High Reference Point for Peer-Performance Comparison. Journal of Accounting Research 56: 581-615.

Festinger, L. 1954. A theory of social comparison processes. Human relations 7 (2): 117-140.

Goette, L., D. Huffman and S. Meier. 2006. The impact of group membership on cooperation and norm enforcement: evidence using random assignment to real social groups. The American Economic Review 96: 212-216.

Hannan, R. L., R. Krishnan, and A. H. Newman. 2008. The effects of disseminating relative performance feedback in tournament and individual performance compensation plans. The Accounting Review 83 (4): 893-913.

Hannan, R. L., G. P. McPhee, A. H. Newman, and I. D. Tafkov. 2013. The effect of relative performance information on performance and effort allocation in a multi-task environment. The Accounting Review 88: 553-575.

Heinle, M. S., C. Hofmann, and A. H. Kunz. 2012. Identity, incentives, and the value of information. The Accounting Review 87: 1309-1334.

Hensvik, L., and O. N. Skans. 2016. Social networks, employee selection, and labor market outcomes. Journal of Labor Economics 34: 825-867.

Hinkin, T. R. 1998. A brief tutorial on the development of measures for use in survey questionnaires. Organizational Research Methods 1: 104-121.

Hogg, M. A. 2006. Social identity theory. In Contemporary Social Psychological Theories, edited by P. J. Burk, 111-136. Stanford, CA: Stanford University Press.

Hogg, M. A., and D. I. Terry. 2000. Social identity and self-categorization processes in organizational contexts. Academy of Management Review 25: 121-140.

Ichniowski, C., K. Shaw, and G. Prennushi. 1997. The effects of human resource practices on manufacturing performance: A study of steel finishing lines. American Economic Review 3: 291-313. 
Johnson, M. D., F. P. Morgeson, D. R. Ilgen, C. J. Meyer, and J. W. Lloyd. 2006. Multiple professional identities: Examining differences in identification across work-related targets. Journal of Applied Psychology 91: 498-506.

Kim, H., and H. R. Markus. 1999. Deviance or uniqueness, harmony or conformity? A cultural analysis. Journal of Personality and Social Psychology 77 (4): 785-800.

Lattin, J., J. D. Carrol., and P. E. Green. 2003. Analyzing Multivariate Data. London: Thomson Learning.

Maas, V. S., and H. Yin. 2018. Finding Partners in Crime? How Internal Transparency Affects Employee Collusion. Working Paper. Accessed from: https://www.wiwi.huberlin.de/de/professuren/bwl/cofi/seminars/17s/maas_2017.pdf

Maas, V. S., and M. Van Rinsum. 2013. How control system design influences performance misreporting. Journal of Accounting Research 51: 1159-1186.

Mael, F., and B. E. Ashforth. 1992. Alumni and their alma mater: A partial test of the reformulated model of organizational identification. Journal of Organizational Behavior 13: 103-123.

Milgrom, P. and J. Roberts. 1990. The economics of modern manufacturing: Technology, strategy, and organization. American Economic Review 3: 511-528.

Milgrom, P. and J. Roberts. 1995. Complementarities and fit strategy, structure, and organizational change in manufacturing. Journal of Accounting and Economics 2-3: 179-208.

Nagar, V. 2002. Delegation and incentive compensation. The Accounting Review 2: 379-395.

Romar, E. J. 2002. Virtue is good business: Confucianism as a practical business ethics. Journal of Business Ethics 38(1-2): 119-131.

Shamir, B., and R. Kark. 2004. A single-item graphic scale for the measurement of organizational identification. Journal of Occupational and Organizational Psychology 77: 115-123.

Slikwa, D. 2007. Trust as a signal of a social norm and the hidden costs of incentive schemes. The American Economic Review 97: 999-1012.

Smith, W. P., and G. B. Arnkelsson. 2000. Stability of related attributes and the in reference of ability through social comparison. In Handbook of Social Comparison: Theory and Research, edited by J. Suls and L. Wheeler, 173-200. New York, NY: Kluwer Academic/Plenum Publishers.

Steelman, L. A., and K. A. Rutkowski. 2004. Moderators of employee reactions to negative feedback. Journal of Managerial Psychology 19: 6-18.

Tafkov, I. D. 2013. Private and public relative performance information under different compensation contracts. The Accounting Review 88: 327-350.

Tajfel, H., and J. C. Turner. 1986. The social identity theory of intergroup behaviour. Psychology of intergroup relations. Chicago: Nelson Hall.

Tayler, W. B. and R. Bloomfield. 2011. Norms, conformity, controls. Journal of Accounting Research 49: 753-790.

Taylor, P. J., and J. L. Pierce. 1999. Effects of introducing a performance management system on employees' subsequent attitudes and effort. Public Personnel Management 28: 423-452.

Terry, D. J., M. A. Hogg, and K. M. White. 1999. The theory of planned behavior: Self-identity, social identity and group norms. British Journal of Social Psychology 38: 225-244.

Towry, K. L. 2003. Control in a teamwork environment-The impact of social ties on the effectiveness of mutual monitoring contracts. The Accounting Review 78: 1069-1095.

Van Der Stede, W. A., S. M. Young, and C. X. Chen. 2005. "Assessing the quality of evidence in empirical management accounting research: The case of survey studies." Accounting, Organizations and Society 30: 655-684. 
TABLE 1

Descriptive Statistics

\begin{tabular}{|c|c|c|c|c|c|c|}
\hline \multicolumn{7}{|c|}{ Panel A: Descriptive Statistics (Full Sample) } \\
\hline Variable & $\mathrm{N}$ & Mean & Median & s.d. & Min & Max \\
\hline Performance & 2,217 & 25.54 & 23.30 & 15.34 & 0.00 & 55.10 \\
\hline PerGap & 2,116 & 13.06 & 9.80 & 11.35 & 0.00 & 55.10 \\
\hline GI & 2,217 & 0.12 & 0.19 & 0.46 & -1.45 & 1.13 \\
\hline Transparent & 2,217 & 0.34 & 0.00 & 0.47 & 0.00 & 1.00 \\
\hline Skill & 2,217 & 1.89 & 2 & 0.76 & 0 & 3 \\
\hline Age & 2,217 & 40.86 & 41.52 & 5.64 & 24.27 & 55.50 \\
\hline Tenure & 2,217 & 21.59 & 23.39 & 5.64 & 0.50 & 30.64 \\
\hline Horizon & 2,217 & 0.09 & 0 & 0.28 & 0 & 1 \\
\hline Gender & 2,217 & 0.21 & 0 & 0.41 & 0 & 1 \\
\hline Local & 2,217 & 0.57 & 1 & 0.50 & 0 & 1 \\
\hline$E d u$ & 2,217 & 1.00 & 1 & 0.64 & 0 & 2 \\
\hline Politics & 2,217 & 0.17 & 0 & 0.37 & 0 & 1 \\
\hline Kinship & 2,217 & 0.45 & 0 & 0.50 & 0 & 1 \\
\hline Referral & 2,217 & 0.34 & 0 & 0.47 & 0 & 1 \\
\hline PMRS & 2,217 & 0.17 & 0.56 & 0.76 & -1.88 & 1.30 \\
\hline \multicolumn{7}{|c|}{ Panel B: Variation of Performance in Groups with Low vs. High Performance Transparency } \\
\hline & \multicolumn{2}{|c|}{$\begin{array}{l}\text { Low Transparency } \\
(\text { Transparent }=0)\end{array}$} & \multicolumn{2}{|c|}{$\begin{array}{c}\text { High Transparency } \\
(\text { Transparent }=1)\end{array}$} & & Difference \\
\hline Variable & $\mathrm{N}$ & s.d. & $\mathrm{N}$ & s.d. & & s.d. \\
\hline Performance & 1,472 & 10.95 & 745 & 8.93 & & $-2.02 *$ \\
\hline
\end{tabular}

Panel A of Table 1 presents the descriptive statistics of employees' performance level (Performance), performance gap (PerGap), group identity (GI), and the control variables. The data of employee performance, Performance, is on a monthly basis. The sample includes 51 employees and 2,217 performance observations from January 2011 to July 2015. PerGap is constructed based on current and lagged performance. This is why it has less observations than other variables. The performance and personnel data are extracted from the database of the research site. Group identity and other control variables are measured using survey questionnaires, details of which are presented in Appendix 3.

Panel B of Table 1 compares the variation of Performance in groups with different performance reporting choices. As we employed a panel dataset, we are able to observe the variation between employees, the variation across time, and the overall variation within each type of reporting choice. Here, we focus on the variation between employees, as it tells us about the homogeneity of employees' performance within each performance reporting choice. This is consistent with our research purpose of examining the effect of group identity in groups with different levels of performance transparency. $*, * *, * * *$ indicates significance at the $10 \%, 5 \%$ and $1 \%$ levels, respectively. For definitions of variables, see Appendix 4. 
TABLE 2

Pearson Correlations

\begin{tabular}{|c|c|c|c|c|c|c|c|c|c|c|c|c|c|c|c|}
\hline & 1. & 2. & 3. & 4. & 5. & 6. & 7. & 8. & 9. & 10. & 11. & 12. & 13. & 14. & 15. \\
\hline 1. Performance & 1.00 & & & & & & & & & & & & & & \\
\hline 2. PerGap & 0.60 & 1.00 & & & & & & & & & & & & & \\
\hline 3. Transparent & -0.22 & 0.00 & 1.00 & & & & & & & & & & & & \\
\hline 4. $G I$ & -0.16 & -0.00 & 0.28 & 1.00 & & & & & & & & & & & \\
\hline 5. Skill & 0.27 & 0.17 & -0.00 & 0.06 & 1.00 & & & & & & & & & & \\
\hline 6. Age & -0.15 & -0.05 & 0.10 & 0.18 & -0.39 & 1.00 & & & & & & & & & \\
\hline 7. Tenure & -0.14 & -0.05 & 0.11 & 0.23 & -0.29 & 0.93 & 1.00 & & & & & & & & \\
\hline 9. Gender & -0.22 & -0.20 & -0.29 & -0.06 & 0.00 & -0.10 & -0.05 & 0.07 & 1.00 & & & & & & \\
\hline 10. Local & 0.06 & 0.03 & 0.17 & 0.00 & -0.13 & 0.36 & 0.41 & 0.16 & -0.15 & 1.00 & & & & & \\
\hline 11. $E d u$ & 0.06 & -0.03 & -0.02 & -0.17 & 0.18 & -0.39 & -0.35 & -0.15 & 0.11 & -0.33 & 1.00 & & & & \\
\hline 12. Politics & -0.05 & 0.00 & 0.30 & 0.27 & -0.15 & 0.06 & 0.01 & 0.09 & -0.24 & 0.20 & 0.14 & 1.00 & & & \\
\hline 13. Kinship & -0.13 & -0.12 & 0.21 & 0.05 & -0.31 & 0.23 & 0.22 & 0.14 & -0.02 & 0.20 & -0.17 & 0.09 & 1.00 & & \\
\hline 14. Referral & -0.08 & -0.12 & -0.09 & -0.04 & -0.29 & 0.41 & 0.41 & 0.09 & -0.07 & 0.09 & -0.08 & 0.07 & 0.04 & 1.00 & \\
\hline 15. PMRS & -0.20 & -0.04 & 0.29 & 0.46 & 0.02 & 0.30 & 0.30 & 0.15 & 0.01 & -0.05 & -0.19 & 0.13 & 0.11 & 0.05 & 1.00 \\
\hline
\end{tabular}

Table 2 presents the pairwise correlation coefficients between the variables. Correlations that are significant at a $10 \%$ significance level or lower are reported in bold. For definitions of variables, see Appendix 4. 


\section{TABLE 3}

Employees' Group Identity and Performance Level

\begin{tabular}{|c|c|c|c|c|}
\hline & \multicolumn{4}{|c|}{$D V=$ Performance Level (Performance) } \\
\hline & $(1)$ & $(2)$ & $(3)$ & (4) \\
\hline & $\begin{array}{c}\text { Full } \\
\text { Sample }\end{array}$ & $\begin{array}{c}\text { Full } \\
\text { Sample }\end{array}$ & $\begin{array}{c}\text { Low } \\
\text { Transparency }\end{array}$ & $\begin{array}{c}\text { High } \\
\text { Transparency }\end{array}$ \\
\hline \multicolumn{5}{|c|}{ Variables of Interest } \\
\hline GI & $\begin{array}{c}2.46 \\
(0.77)\end{array}$ & $\begin{array}{c}5.93 * * * \\
(2.72)\end{array}$ & $\begin{array}{l}4.87 * \\
(1.87)\end{array}$ & $\begin{array}{c}-6.19 * * * \\
(-3.10)\end{array}$ \\
\hline Transparent & $\begin{array}{c}-8.29 * * * \\
(-3.12)\end{array}$ & $\begin{array}{l}-3.82 \\
(-1.24)\end{array}$ & & \\
\hline GI $\times$ Transparent & & $\begin{array}{c}-12.32 * * * \\
(-3.98)\end{array}$ & & \\
\hline \multicolumn{5}{|c|}{ Demographic Characteristics } \\
\hline Skill & $\begin{array}{c}1.93 \\
(1.51)\end{array}$ & $\begin{array}{c}0.77 \\
(0.61)\end{array}$ & $\begin{array}{l}3.11 * \\
(1.90)\end{array}$ & $\begin{array}{c}7.77 * * * \\
(3.64)\end{array}$ \\
\hline Age & $\begin{array}{l}-0.20 \\
(-0.76)\end{array}$ & $\begin{array}{c}-0.18 \\
(-0.68)\end{array}$ & $\begin{array}{c}0.13 \\
(0.33)\end{array}$ & $\begin{array}{c}-0.20 \\
(-0.58)\end{array}$ \\
\hline Horizon & $\begin{array}{c}2.04 \\
(0.83)\end{array}$ & $\begin{array}{c}2.32 \\
(0.95)\end{array}$ & $\begin{array}{c}2.17 \\
(0.85)\end{array}$ & $\begin{array}{c}6.06 \\
(1.19)\end{array}$ \\
\hline Gender & $\begin{array}{c}-14.21 * * * \\
(-6.64)\end{array}$ & $\begin{array}{c}-13.27 * * * \\
(-6.41)\end{array}$ & $\begin{array}{c}-13.71 * * * \\
(-5.22)\end{array}$ & $\begin{array}{l}-9.73 \\
(-1.54)\end{array}$ \\
\hline Local & $\begin{array}{c}3.97 \\
(1.21)\end{array}$ & $\begin{array}{c}3.88 \\
(1.29)\end{array}$ & $\begin{array}{l}5.65 * \\
(1.69)\end{array}$ & $\begin{array}{c}2.16 \\
(0.70)\end{array}$ \\
\hline$E d u$ & $\begin{array}{c}2.23 \\
(1.09)\end{array}$ & $\begin{array}{c}2.32 \\
(1.36)\end{array}$ & $\begin{array}{c}6.61 * * * \\
(3.84)\end{array}$ & $\begin{array}{l}-3.40 * \\
(-1.84)\end{array}$ \\
\hline Politics & $\begin{array}{c}-3.16 \\
(-1.55)\end{array}$ & $\begin{array}{l}-3.74 * \\
(-1.84)\end{array}$ & $\begin{array}{c}-3.20 \\
(-0.99)\end{array}$ & $\begin{array}{c}0.66 \\
(0.33)\end{array}$ \\
\hline Connections & & & & \\
\hline Kinship & $\begin{array}{c}-3.76 \\
(-1.34)\end{array}$ & $\begin{array}{l}-3.45 \\
(-1.26)\end{array}$ & $\begin{array}{l}-4.52 * \\
(-1.89)\end{array}$ & $\begin{array}{c}-2.32 \\
(-0.80)\end{array}$ \\
\hline Referral & $\begin{array}{l}-1.32 \\
(-0.58)\end{array}$ & $\begin{array}{c}-2.41 \\
(-1.06)\end{array}$ & $\begin{array}{c}-3.32 \\
(-1.11)\end{array}$ & $\begin{array}{c}-0.36 \\
(-0.16)\end{array}$ \\
\hline Perception & & & & \\
\hline$P M R S$ & $\begin{array}{l}2.12 * \\
(1.74)\end{array}$ & $\begin{array}{c}1.04 \\
(1.02)\end{array}$ & $\begin{array}{c}0.15 \\
(0.14)\end{array}$ & $\begin{array}{c}2.48 \\
(1.01)\end{array}$ \\
\hline
\end{tabular}


TABLE 3 - (continued.)

\begin{tabular}{|c|c|c|c|c|}
\hline & (1) & (2) & (3) & (4) \\
\hline Time fixed effects & Controlled & Controlled & Controlled & Controlled \\
\hline Group fixed effects & Controlled & Controlled & Controlled & NA \\
\hline Cluster-Robust $\mathrm{R}^{2}$ & $34.30 \%$ & $35.00 \%$ & $40.70 \%$ & $44.30 \%$ \\
\hline $\mathrm{N}$ & 2,217 & 2,217 & 1,472 & 745 \\
\hline \multicolumn{5}{|c|}{ Table 3 presents the estimated associations between group identity $(G I)$ and the level of employee performance (Performance) } \\
\hline \multicolumn{5}{|c|}{$\begin{array}{c}\text { Performance }_{i t}=\beta_{0}+\beta_{1} G I+\beta_{2} \text { Transparent }_{i}+\beta_{3}\left(\text { GI }_{i} \times \text { Transparent }_{i}\right)+\beta_{4} \text { Skill }_{i}+\beta_{5} \text { Age }_{i t}+\beta_{6} \text { Horizon }_{i t}+\beta_{7} \text { Gender }_{i} \\
+ \\
+\beta_{8} \text { Local }_{i}+\beta 9 \text { Edu }_{i}+\beta_{10} \text { Politics }_{i}+\beta_{11} \text { Kinship }_{i}+\beta_{12} \text { Referral }_{i}+\beta_{13} \text { PMRS }_{i}+\varepsilon_{i t}\end{array}$} \\
\hline \multicolumn{5}{|c|}{$\begin{array}{l}\text { When estimating Model (1), we control for individual random effects and have the standard errors clustered at the individua } \\
\text { level. Columns (1) and (2) present the results estimated using the full sample, which include all the three groups in our setting } \\
\text { Column (3) presents the results estimated using the groups with low performance transparency; and Column (4) presents the } \\
\text { results estimated using the group with high performance transparency. The sample period for all estimations is from January } \\
2011 \text { to July } 2015 \text {. } \\
\text { Difference between the coefficients of } G I \text { when performance transparency is low (Column (3)) and high (Column (4)): } \\
\qquad H_{0}: G I_{\text {low_transparency }}=\text { GI }_{\text {high }} \text { transparency } \\
\qquad z=3.36, p<0.01\end{array}$} \\
\hline
\end{tabular}




\section{TABLE 4}

Employees' Group Identity and Conformity

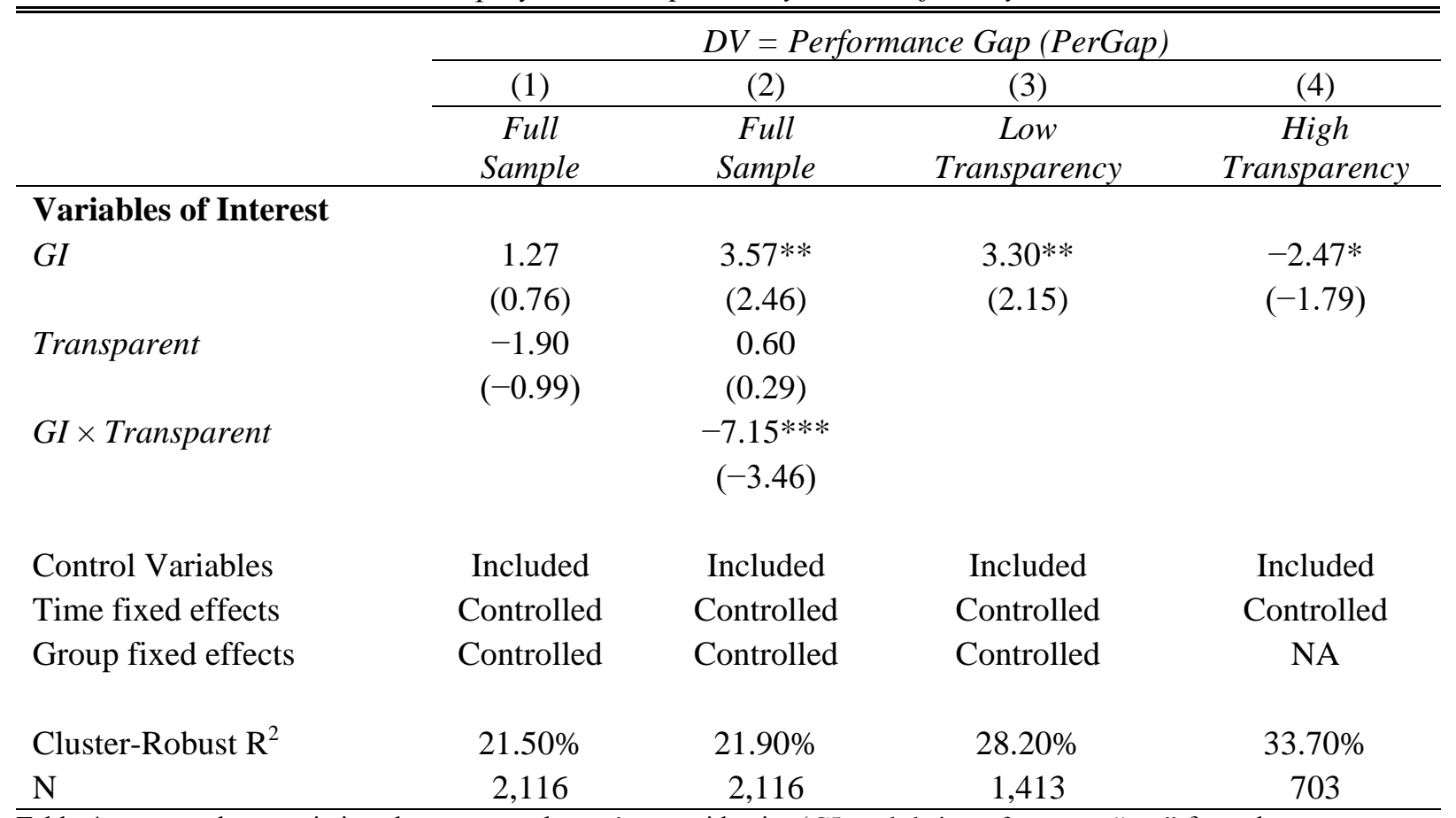

Table 4 presents the associations between employees' group identity $(G I)$ and their performance "gap" from the group norm (PerGap):

$$
\begin{aligned}
\text { PerGap }_{i t} & =\beta_{0}+\beta_{1} \text { GI I }_{i}+\beta_{2} \text { Transparent }_{i}+\beta_{3}\left(\text { GI } \times \text { Transparent }_{i}\right)+\beta_{4} \text { Skill }_{i}+\beta_{5} \text { Age }_{i t}+\beta_{6} \text { Horizon }_{i t}+\beta_{7} \text { Gender }_{i}+\beta_{8} \text { Local }_{i} \\
& +\beta_{9} E d u_{i}+\beta_{10} \text { Politics }_{i}+\beta_{11} \text { Kinship }_{i}+\beta_{12} \text { Referral }_{i}+\beta_{13} \text { PMRS }_{i}+\varepsilon_{i t}
\end{aligned}
$$

PerGap is calculated as the absolute difference between employee performance (Performance) and the perceived group norms (i.e., the average of the group medians in the previous period):

$$
\text { PerGap }_{i t}=\mid \text { Performance }_{i t}-\text { Norm }_{j t}|=| \text { Performance }_{i t}-\text { Median }_{j, t-1} \mid
$$

When estimating Model (2), we control for the individual random effects and have the standard errors clustered at the individual level. Columns (1) and (2) present the results estimated using the full sample, which include all the three groups in our setting. Column (3) presents the results estimated using the groups with low performance transparency; and Column (4) presents the results estimated using the group with high performance transparency. The sample period for all estimations is from January 2011 to July 2015.

Difference between the coefficients of GI when performance transparency is low (Column (3)) and high (Column (4)):

$$
\begin{gathered}
H_{0}: G I_{\text {low_transparency }}=G I_{\text {high_transparency }} \\
z=2.80, p<0.01
\end{gathered}
$$

$*, * *, * * *$ indicate significance at the $10 \%, 5 \%$ and $1 \%$ levels, respectively. For definitions of variables, see Appendix 4. 
TABLE 5

Employees with High versus Low Ability

\begin{tabular}{|c|c|c|c|c|}
\hline & \multicolumn{4}{|c|}{$D V=$ Performance Level (Performance) } \\
\hline & \multicolumn{2}{|c|}{ High Transparency } & \multicolumn{2}{|c|}{ Low Transparency } \\
\hline & $(1)$ & $(2)$ & (3) & (4) \\
\hline & Low-Ability & High-Ability & Low-Ability & High-Ability \\
\hline \multicolumn{5}{|l|}{ Variables of Interest } \\
\hline$G I$ & $\begin{array}{c}31.01 * * * \\
(9.15)\end{array}$ & $\begin{array}{c}-8.40 * * * \\
(-3.07)\end{array}$ & $\begin{array}{l}18.29 \\
(0.67)\end{array}$ & $\begin{array}{c}8.45^{* * *} \\
(2.80)\end{array}$ \\
\hline Control Variables & Included & Included & Included & Included \\
\hline Time fixed effects & Controlled & Controlled & Controlled & Controlled \\
\hline Group fixed effects & NA & NA & Controlled & Controlled \\
\hline Cluster-Robust $\mathrm{R}^{2}$ & $58.40 \%$ & $43.00 \%$ & $44.80 \%$ & $50.40 \%$ \\
\hline $\mathrm{N}$ & 179 & 566 & 424 & 1,048 \\
\hline
\end{tabular}

Table 5 presents the estimated associations between group identity $(G I)$ and employee performance (Performance) in the subsamples of high- and low-ability employees:

$\begin{aligned} \text { Performance }_{i t}= & \beta_{0}+\beta_{1} G_{i}+\beta_{2} \text { Transparent }_{i}+\beta_{3}\left(\text { GI I }_{i} \times \text { Transparent }_{i}\right)+\beta_{4} \text { Skill }_{i}+\beta_{5} \text { Age }_{i t}+\beta_{6} \text { Horizon }_{i t}+\beta_{7} \text { Gender }_{i}+ \\ & \beta_{8} \text { Local }_{i}+\beta_{9} \text { Edu }_{i}+\beta_{10} \text { Politic }_{i}+\beta_{11} \text { Kinship }_{i}+\beta_{12} \text { Referral }_{i}+\beta_{13} \text { PMRS }_{i}+\varepsilon_{\text {eit }}\end{aligned}$

As we divided the sample based on whether performance transparency is high or low, Transparent and the interaction between group identity and Transparent are dropped in the estimation. We controlled the individual random effects and have the standard errors clustered at the individual level. Columns (1) and (2) present the results estimated when performance transparency is high: Column (1) presents the results estimated using the low-ability employees under and Column (2) presents the results estimated using the high-ability employees. Columns (3) and (4) present the results estimated when performance transparency is low: Column (3) presents the results estimated using the low-ability employees and Column (4) presents the results estimated using the high-ability employees. The sample period for all estimations is from January 2011 to July 2015.

Difference between the coefficients of GI between low-ability employees (Column (1)) and high-ability employees (Column (2)) when performance transparency is high:

$$
\begin{gathered}
H_{0}: G_{\text {low-ability }}=G I_{\text {high-ability }} \\
z=-11.32, p<0.01
\end{gathered}
$$

Difference between the coefficients of $G I$ between low-ability employees (Column (3)) and high-ability employees (Column (4)) when performance transparency is low:

$$
\begin{array}{r}
H_{0}: G_{l o w-a b i l i t y}=G I_{\text {high-ability }} \\
z=-0.36, p>0.10
\end{array}
$$

$*, * *, * * *$ indicate significance at the $10 \%, 5 \%$ and $1 \%$ levels, respectively. For definitions of variables, see Appendix 4. 
TABLE 6

Determinants of Group Identity

\begin{tabular}{|c|c|c|c|c|}
\hline & \multicolumn{4}{|c|}{ DV $=$ Group Identity $(G I)$} \\
\hline & $(1)$ & $(2)$ & $(3)$ & (4) \\
\hline & $\begin{array}{c}\text { Sample of } \\
\text { main analysis }\end{array}$ & $\begin{array}{c}\text { Sample of } \\
\text { main analysis }\end{array}$ & $\begin{array}{l}\text { Sample of all } \\
\text { respondents }\end{array}$ & $\begin{array}{l}\text { Sample of all } \\
\text { respondents }\end{array}$ \\
\hline \multicolumn{5}{|c|}{ Performance Transparency } \\
\hline Transparent & $\begin{array}{c}0.02 \\
(0.09)\end{array}$ & $\begin{array}{l}-0.18 \\
(-0.98)\end{array}$ & $\begin{array}{c}0.03 \\
(0.29)\end{array}$ & $\begin{array}{c}0.33 \\
(0.84)\end{array}$ \\
\hline \multicolumn{5}{|c|}{ Demographic Characteristics } \\
\hline Skill & $\begin{array}{c}0.01 \\
(0.12)\end{array}$ & $\begin{array}{c}0.04 \\
(0.56)\end{array}$ & $\begin{array}{c}0.08 \\
(1.10)\end{array}$ & $\begin{array}{c}0.09 \\
(1.26)\end{array}$ \\
\hline Age & $\begin{array}{c}0.02 \\
(0.90)\end{array}$ & $\begin{array}{c}0.02 \\
(0.68)\end{array}$ & $\begin{array}{c}0.01 \\
(0.65)\end{array}$ & $\begin{array}{c}0.02 \\
(1.15)\end{array}$ \\
\hline Horizon & $\begin{array}{l}-0.21 \\
(-0.79)\end{array}$ & $\begin{array}{l}-0.14 \\
(-0.55)\end{array}$ & $\begin{array}{l}-0.24 \\
(-1.61)\end{array}$ & $\begin{array}{l}-0.30 * \\
(-1.78)\end{array}$ \\
\hline Gender & $\begin{array}{c}0.18 \\
(0.81)\end{array}$ & $\begin{array}{c}0.17 \\
(0.82)\end{array}$ & $\begin{array}{c}0.14 \\
(1.19)\end{array}$ & $\begin{array}{c}0.18 \\
(1.28)\end{array}$ \\
\hline Local & $\begin{array}{l}-0.04 \\
(-0.24)\end{array}$ & $\begin{array}{l}-0.02 \\
(-0.14)\end{array}$ & $\begin{array}{c}0.13 \\
(1.27)\end{array}$ & $\begin{array}{c}0.15 \\
(1.33)\end{array}$ \\
\hline$E d u$ & $\begin{array}{l}-0.05 \\
(-0.55)\end{array}$ & $\begin{array}{l}-0.12 \\
(-1.13)\end{array}$ & $\begin{array}{l}-0.05 \\
(-0.62)\end{array}$ & $\begin{array}{l}-0.03 \\
(-0.36)\end{array}$ \\
\hline Politics & $\begin{array}{c}0.35 \\
(1.52)\end{array}$ & $\begin{array}{l}0.41 * \\
(1.70)\end{array}$ & $\begin{array}{c}0.05 \\
(0.41)\end{array}$ & $\begin{array}{c}0.08 \\
(0.54)\end{array}$ \\
\hline Connections & & & & \\
\hline Kinship & $\begin{array}{l}-0.01 \\
(-0.03)\end{array}$ & $\begin{array}{c}0.09 \\
(0.56)\end{array}$ & $\begin{array}{l}0.17 * \\
(1.74)\end{array}$ & $\begin{array}{l}0.17 * \\
(1.68)\end{array}$ \\
\hline Referral & $\begin{array}{l}-0.15 \\
(-1.00)\end{array}$ & $\begin{array}{l}-0.18 \\
(-1.18)\end{array}$ & $\begin{array}{l}-0.01 \\
(-0.05)\end{array}$ & $\begin{array}{l}-0.06 \\
(-0.56)\end{array}$ \\
\hline Perception & & & & \\
\hline PMRS & $\begin{array}{l}0.27 * \\
(1.81)\end{array}$ & $\begin{array}{c}0.18 \\
(1.22)\end{array}$ & $\begin{array}{c}0.29 * * * \\
(4.31)\end{array}$ & $\begin{array}{c}0.24 * * * \\
(3.36)\end{array}$ \\
\hline Intercept & $\begin{array}{l}-0.83 \\
(-0.85)\end{array}$ & $\begin{array}{c}-0.44 \\
(-0.46)\end{array}$ & $\begin{array}{c}-0.63 \\
(-0.95)\end{array}$ & $\begin{array}{c}-1.68 * * * \\
(-3.05)\end{array}$ \\
\hline Group fixed effects & No & Controlled & No & Controlled \\
\hline Robust $\mathrm{R}^{2}$ & $\begin{array}{c}36.00 \% \\
49\end{array}$ & $\begin{array}{c}42.50 \% \\
49\end{array}$ & $\begin{array}{c}16.00 \% \\
254\end{array}$ & $\begin{array}{c}22.80 \% \\
254\end{array}$ \\
\hline
\end{tabular}

Table 6 presents the estimated relations between employees' group identity and other variables. Results estimated based on the sample of the main analysis are presented in Columns (1) and (2), and the results estimated based on all the survey respondents are presented in Columns (3) and (4).

$*, * *, * * *$ indicate significance at the $10 \%, 5 \%$ and $1 \%$ levels, respectively. For definitions of variables, see Appendix 4. 


\section{University Library}

\section{- M M I E E R VA A gateway to Melbourne's research publications}

Minerva Access is the Institutional Repository of The University of Melbourne

Author/s:

Shang, R;Abernethy, M;Hung, C-Y

Title:

Group Identity, Performance Transparency, and Employee Performance

Date:

2020-09-01

Citation:

Shang, R., Abernethy, M. \& Hung, C. -Y. (2020). Group Identity, Performance Transparency, and Employee Performance. The Accounting Review, 95 (5), pp.373-397. https:// doi.org/10.2308/accr-52652.

Persistent Link:

http://hdl.handle.net/11343/258719 